\title{
Anti-arthritic effect of chicken embryo tissue hydrolyzate against adjuvant arthritis in rats (X-ray microtomographic and histopathological analysis)
}

\author{
Igor Rzhepakovsky ${ }^{1}$, Svetlana Avanesyan1, Mehmet Benlidayi ${ }^{7}$, Kunaal Dhingra ${ }^{8}$, Alexander \\ Dolgalev $^{4,5}$, Natella Enukashvily, Tilman Fritsch ${ }^{5}$, Stanislav Kochergin ${ }^{3}$, Marina Sizonenko ${ }^{1}$, \\ Lyudmila Timchenko1, Marko Vukovic ${ }^{5}$, Sergey Piskov, and Wolf-Dieter Grimm ${ }^{2,5 *}$ \\ 1 Institute of Live Science, North Caucasus Federal University, 355017 Stavropol, Russia; 78igorr@mail.ru \\ (I.R.); piskovsi77@mail.ru (S.P.); 1_timchenko@mail.ru (L.T.); s.avanesan@yandex.ru (S.A.); \\ risha_veresk@mail.ru (M.S.) \\ 2 Periodontology, School of Dental Medicine, Faculty of Health, Witten/Herdecke University, \\ A.-Herrhausen-Street 50, 58448Witten, Germany; prof_wolf.grimm@yahoo.de \\ 3 LTD InCome, Tukhachevskogo st. 26/1, 355035 Stavropol, Russian Federation; wwwstas@yandex.ru \\ 4 Department of General Dentistry and Pediatric Dentistry, Stavropol State Medical University, 355017 \\ Stavropol, Russia; dolgalev@dolgalev.pro \\ 5 Center for Innovation and Technology Transfer at Stavropol State Medical University, Stavropol, Russian \\ Federation; 355017 Stavropol, Russia, prof_wolf.grimm@yahoo.de; dolgalev@dolgalev.pro; \\ prof.vuk@web.de; tilmanf@hotmail.com \\ 6 Institute of Cytology, Russian Academy of Sciences, St. Petersburg, 194064 Russia; natellae@gmail.com \\ 7 Faculty of Dentistry, Cukurova University, Department of Oral and Maxillofacial Surgery Turkey; 1111, \\ 01330 Adana; emrebenlidayi@yahoo.com \\ 8 Division of Periodontics, Centre for Dental Education and Research, All India Institute of Medical Sciences, \\ New Delhi, India, 110029; kunaaldhingra@yahoo.co.in \\ * Correspondence: prof_wolf.grimm@yahoo.de; Tel.: +49-173 1428909
}

\begin{abstract}
Finding new, safe strategies to prevent and control rheumatoid arthritis is an urgent task. Of particular interest in this regard are bioactive peptides and peptide-rich protein hydrolyzates, which represent a new trend in the development of functional foods and nutraceuticals. The resulting tissue hydrolyzate of the chicken embryo (CETH) has been evaluated for acute toxicity and tested against chronic arthritis induced by Freund's full adjuvant in rats. The anti-arthritic effect of CETH was studied on the 28th day of the experiment after two weeks of oral administration of CETH at doses of 60 and $120 \mathrm{mg} / \mathrm{kg}$ body weight. Arthritis was evaluated on the last day of the experiment on the injected animal paw using X-ray computerized microtomography and histopathology analysis methods. The CETH effect was compared with the non-steroidal anti-inflammatory drug diclofenac sodium $(5 \mathrm{mg} / \mathrm{kg}$ ). Oral administration of CETH was accompanied by effective dose-dependent correction of morphological changes caused by the adjuvant injection. CETH had relatively high recovery effects in terms of parameters for reducing inflammatory edema, inhibition of osteolysis, prevention of osteophitosis, reduction of the inflammatory reaction of periarticular tissues, and cartilage degeneration. This study presents a potential theoretical strategy for the safe correction of this pathological process and, for the first time, shows that CETH may be a powerful potential nutraceutical agent or bioactive component of functional products in the treatment of rheumatoid arthritis.
\end{abstract}

Keywords: chicken embryo tissue, hydrolysate, food-derived bioactive peptides, adjuvant arthritis, anti-arthritic effect, in vitro and in vivo assays, $\mathrm{X}$-ray microtomography, histopathological analysis

\section{Introduction}


Rheumatoid arthritis is the most frequent autoimmune disease and ranks first among inflammatory joint lesions [1]. It is a severe chronic non-inflammatory disease, which is characterized by inflammation accompanied by the destruction of joint structures, lesions of parotid tissues, and bones [2,3]. Rheumatoid arthritis is characterized by a chronic course, steady progress, and a high prevalence of concomitant diseases, which significantly reduces the general functional status, quality of life and is one of the main reasons for early disability [4,5].

The etiopathogenesis of rheumatoid arthritis is very complex and has been under active study for many years [6,7]. Today, non-steroidal anti-inflammatory drugs (NSAID), disease-modifying anti rheumatoid drugs (DMARD), corticosteroids, and biological agents are the primary agents used to alleviate symptoms and slow the progression of rheumatoid arthritis [8,9]. Regarding the cellular component of tissue engineering, NCSCs have been the focus of many efforts for cartilage regeneration. NCSCs are widely available from diverse tissues and are capable of expansion (self-renewal) and multi-lineage differentiation into bone, cartilage, fat, muscle, and nerve [10-12].

However, the use of stem cell-derived therapeutics, NSAID, DMARD and, corticosteroids has a fairly wide range of contraindications and can be accompanied by a range of adverse reactions, often limiting their clinical use $[13,14]$. Therapy with biological drugs with high pharmacological selectivity and fewer side effects is very expensive, and not many patients can afford it [15].

All this determines the importance of finding other effective, safe, and inexpensive strategies to combat rheumatoid arthritis. In autoimmune diseases like rheumatoid arthritis or systemic lupus erythematosus, the immune system turns against its own body and triggers inflammation. The International Society for Cellular and Gene Therapies (ISCT) and the International Society for Extracellular Vesicles (ISEV) recognize the potential of extracellular vesicles (EVs, including exosomes) from mesenchymal stromal cells (MSCs) and possibly other cell sources as treatments for OA [16-21]. The focus is shifting towards natural alternatives [22-25].

Perinatal tissues are of particular interest in this respect. The available literature increasingly mentions the anti-arthritic effect of placental tissues [26-28]. Bioactive peptides and amino acids contained in placental tissues ensure their high biological and functional activity [29]. Components of the placenta have expressed anti-inflammatory and antioxidant properties [30,31] and possess anti-apoptotic, anti-osteoporotic, and regenerative effects [32-34]. However, the use of placental tissues has economic, technological, epidemic, and ethical limitations. Therefore, in the scientific and industrial environment, there is no interest in finding alternative raw materials cheaper, more accessible, faster reproducible, epidemiologically safe, but no less rich in biologically active compounds, especially protein and peptide nature. As such, a source of raw materials are now increasingly considered embryonic and extraembryonic tissues of birds, which are chemically not inferior to tissues of the placenta of humans and animals, and substances based on them in some countries are already used as effective nutraceuticals [35,36].

Hatching at different stages of a bird's egg is rich in peptides of different embryo tissues, including highly active peptides of poly-directional muscles with carnosine, anzerine [37], as well as functionally active amino acids of glutamate family, in particular hydroxyproline [38].

Recent studies have shown that extracts of chicken embryonic and extraembryonic tissues have a pronounced anti-inflammatory effect [39]. Components of chicken embryonic tissues have high antioxidant and immunomodulatory properties [40-42].

In previous studies in vivo experiments, we have shown the anti-inflammatory effect of bio preparations developed based on embryonic egg mass of birds [43,44]. In in vitro experiments, we demonstrated antioxidant properties of peptide-containing extracts of chicken embryonic tissues obtained by different hydrolysis methods [38].

However, despite the already confirmed biologically active properties of various substances based on chicken embryonic tissue, there is no information on their possible efficacy in rheumatoid arthritis in humans or laboratory animals. However, their component composition, especially the peptide-amino acid profile, has serious potential in this regard. 
Therefore, the purpose of this study was to study the anti-arthritic effect of chicken embryo tissue hydrolyzate (CETH) in adjuvant-induced joint damage in rats, which is the closest possible model of rheumatoid arthritis in humans.

\section{Results}

\subsection{In-vitro anti-arthritic activity}

The study of CETH in vitro anti-arthritic activity included assessing inhibition of protein denaturation, the effect on membrane stabilization, and proteinase inhibitory activity. The study was performed for three different concentrations of CETH $(3.75 \mathrm{mg} / \mathrm{ml} ; 7.5 \mathrm{mg} / \mathrm{ml} ; 15.0 \mathrm{mg} / \mathrm{ml})$ compared to a single dose of diclofenac sodium $(200 \mathrm{mcg} / \mathrm{ml})$. The results are presented in the table below.

Table 1. Percent inhibition of different in vitro-anti-arthritic model of diclofenac sodium (200 $\mathrm{mcg} / \mathrm{ml})$, CETH $(3.75 \mathrm{mg} / \mathrm{ml})$, CETH $(7.5 \mathrm{mg} / \mathrm{ml})$, CETH $(15.0 \mathrm{mg} / \mathrm{ml})$.

\begin{tabular}{cccc}
\hline Treatment & $\begin{array}{c}\text { Protein } \\
\text { denaturation (\%) }\end{array}$ & $\begin{array}{c}\text { Membrane } \\
\text { stabilization (\%) }\end{array}$ & $\begin{array}{c}\text { Proteinase } \\
\text { inhibition (\%) }\end{array}$ \\
\hline Diclofenac sodium & $66.36 \pm 1.67^{\mathrm{a}}$ & $58.42 \pm 0.63^{\mathrm{a}}$ & $91,37 \pm 2,18^{\mathrm{a}}$ \\
$(200 \mathrm{mcg} / \mathrm{ml})$ & $44.35 \pm 1.12^{\mathrm{b}}$ & $4.52 \pm 0.11 \mathrm{~b}$ & $29.14 \pm 0.73 \mathrm{~b}$ \\
CETH $(3.75 \mathrm{mg} / \mathrm{ml})$ & $66.70 \pm 1.70^{\mathrm{a}}$ & $30.47 \pm 0.76^{\mathrm{c}}$ & $77.0 \pm 1.93^{\mathrm{c}}$ \\
CETH $(7.5 \mathrm{mg} / \mathrm{ml})$ & $91.20 \pm 2.28^{\mathrm{c}}$ & $62.63 \pm 1.57^{\mathrm{a}}$ & $87.42 \pm 2.24^{\mathrm{a}}$ \\
\hline CETH $(15.0 \mathrm{mg} / \mathrm{ml})$ &
\end{tabular}

Different superscript letters indicate statistically significant differences between the means $(\mathrm{P}<0.05)$ for each parameter.

Protein denaturation is an etiopathogenesis proven mechanism of inflammation and development of rheumatoid arthritis. CETH showed high activity regarding protein denaturation inhibition. In the concentration of $7.5 \mathrm{mg} / \mathrm{ml}$, CETH showed the same effect as diclofenac of sodium, and in the concentration of $15.0 \mathrm{mg} / \mathrm{ml}$, it was significantly higher.

As erythrocyte membranes are similar to components of lysosomal membranes, inhibition of hypotonicity and lysis of erythrocyte membranes was taken as a measure of anti-inflammatory activity mechanism.

CETH in doses $7.5 \mathrm{mg} / \mathrm{ml}$ and $15.0 \mathrm{mg} / \mathrm{ml}$ effectively inhibited hemolysis induced by the hypotonic medium. In the concentration of $15.0 \mathrm{mg} / \mathrm{ml}$, CETH showed membrane stabilizing activity on the same level as sodium diclofenac.

Proteinases are known to participate in the pathogenesis of arthritis. Leukocyte proteinases play an essential role in the development of tissue damage during inflammatory reactions. Accordingly, protection is provided by proteinase inhibitors [45]. In this study, the inhibitory activity of trypsin was assessed since it is believed that it is trypsin that activates during the development of rheumatoid arthritis [46].

According to the results, the leading position in terms of the proteinase inhibitory effect was of sodium diclofenac. CETH $(7.5 \mathrm{mg} / \mathrm{ml})$ showed dose-dependent activity, and in a concentration of $15.0 \mathrm{mg} / \mathrm{ml}$, it was close to the comparison drug in terms of activity.

\subsection{Acute oral toxicity}

After oral administration of CETH at a dose of $2000 \mathrm{mg} / \mathrm{kg}$ of body weight, no visible signs of toxicity were observed in animals. No cases of mortality have been registered. Pathomorphological assessment of animals after 14 days of observation did not reveal any pathological changes.

Two doses of CETH 60 and $120 \mathrm{mg} / \mathrm{kg}$ of body weight were selected for further investigation $e x$ vivo on white rats. 


\subsection{Micro-CT analysis}

The size of paw edema is one of the main criteria for assessing the anti-arthritic activity of drugs in adjuvant-induced arthritis. The volume of the paws was measured by micro-CT and calculated using the CTAn software (version: 1.18.4.0, Bruker, Kontich, Belgium), visualization was performed in the CTvox software (3.3.0r1403, Bruker-microCT, Belgium).

In animals with adjuvant injection on the last 28th day of the experiment, pronounced peripheral edema of the injected paw was preserved (Figures $1 b, f)$, which has been repeatedly described earlier in the work of other researchers [47].

As expected, the use of diclofenac demonstrated a noticeable therapeutic efficacy in adjuvant arthritis, in the form of an evident decrease in the swelling of the injected paw. The percentage of reduced inflammatory edema in Group III was 21.1\% (Figure 1c,f).

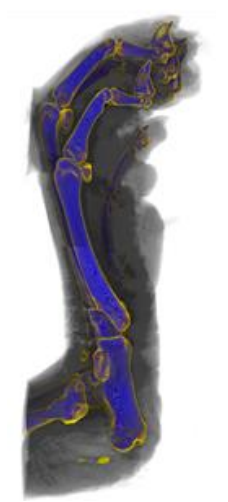

(a)

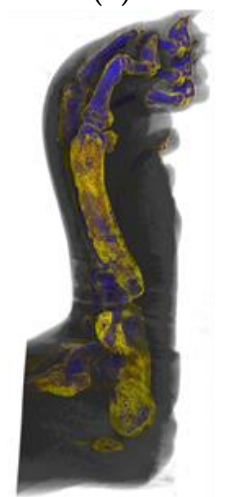

(d)

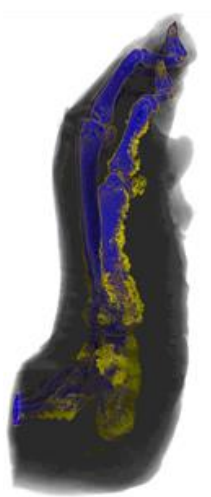

(b)

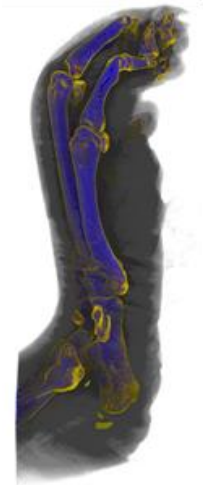

(e)

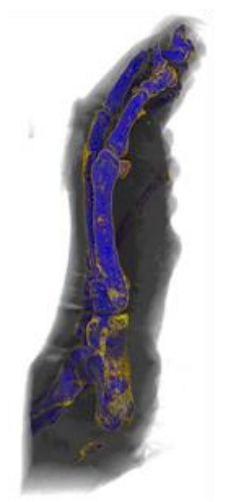

(c)

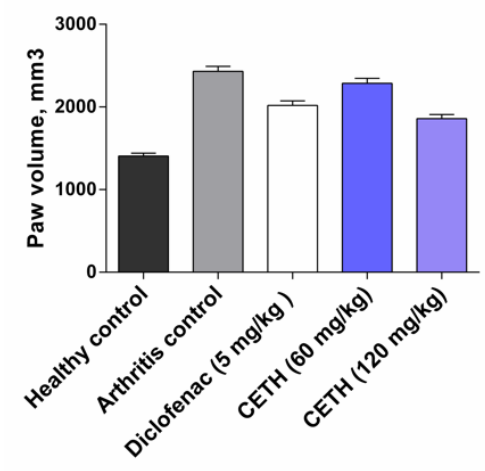

(f)

Figure 1. X-ray microtomograms of representative hind paws of $r$ rats from five groups on day 28: (a) Group I - healthy control; (b) Group II - arthritis control; (c) Group III - arthritis with Diclofenac sodium (5 mg/kg) treatment; (d) Group IV - arthritis with CETH (60 mg/kg) treatment; (e) Group V arthritis with CETH $(120 \mathrm{mg} / \mathrm{kg})$ treatment; (f) Injected paw volume (values represents shown as $\mathrm{m} \pm$ SEM).

Representative X-ray microtomograms on Figures $2 \mathrm{~d}$,e show that in comparison with the model group II, the use of CETH animals was also accompanied by a decrease in swelling. In group IV animals, the percentage of inhibition of inflammatory paw edema was $8.1 \%$. The efficiency of CETH in the dose of $120 \mathrm{mg} / \mathrm{kg}$ was comparable to that of diclofenac and even slightly higher (23.5\%).

Bone mass loss and remodeling caused by joint inflammation are the hallmarks of rheumatoid arthritis and are easily detected by measuring the mineral density of bone (BMD). The use of micro-CT in this regard is a powerful tool and makes the BMD data a reliable biomarker with high sensitivity for the evaluation of antirheumatic drugs [48]. 
The value of trabecular BMD metaphyses of tibia obtained by micro-CT in control group animals was $773.48 \pm 19.32 \mathrm{mg} / \mathrm{cm}^{3}$. In rats of group II compared to healthy control, there was a loss of trabecular BMD by $16,2 \%\left(648,13 \pm 15,80 \mathrm{mg} / \mathrm{cm}^{3}\right)$. In animals receiving diclofenac and CETH in dose $60 \mathrm{mg} / \mathrm{kg}$, BMD values exceeded those of Group II and were $730.48 \pm 18.72$ and $752.65 \pm 18.85$ $\mathrm{mg} / \mathrm{cm}^{3}$. The value of trabecular BMD in group $\mathrm{V}$ of animals after application of CETH in a dose of $120 \mathrm{mg} / \mathrm{kg}$ was as close to the control value as possible and was $772.24 \pm 19.41 \mathrm{mg} / \mathrm{cm}^{3}$.

The obtained micro-CT images of the rat ankle joint area represented non-destructive visualization of changes that occurred. The frontal slices of the joints are shown in the picture. The bones forming the joint, namely the distal parts of the tibia and fibula, and the joint space are clearly shown (Figure 2).

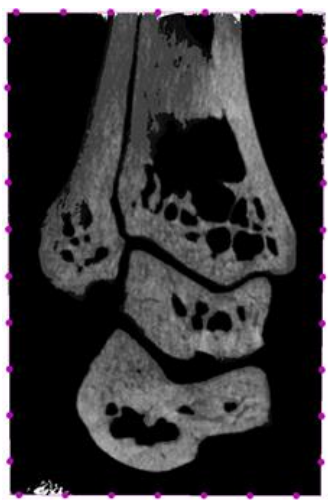

(a)

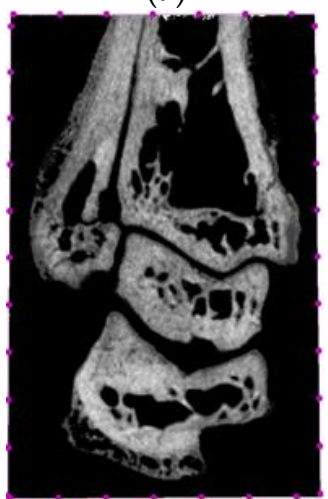

(d)

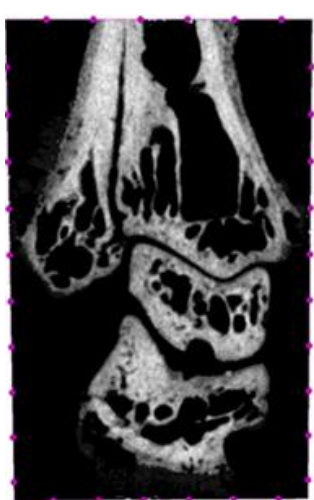

(b)

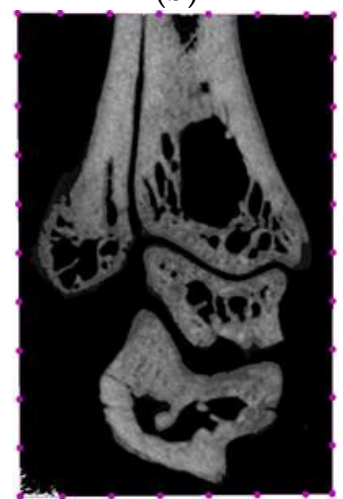

(e)

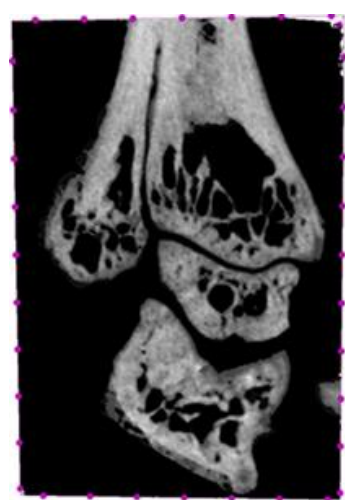

(c)

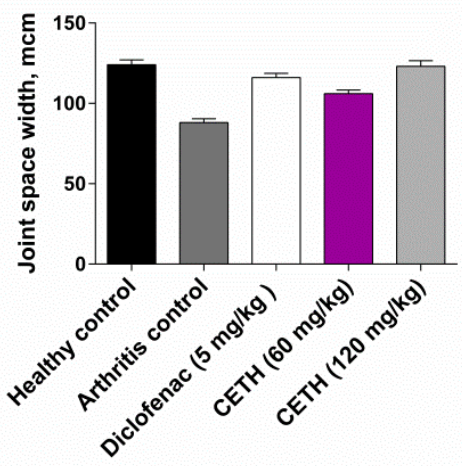

(f)

Figure 2. Micro-CT image of the ankle joint of rats. Frontal slice: (a) Group I - healthy control; (b) Group II - arthritis control; (c) Group III - arthritis with Diclofenac sodium (5 mg/kg) treatment; (d) Group IV - arthritis with CETH (60 mg/kg) treatment; (e) Group V - arthritis with CETH (120 mg/kg) treatment; (f) Joint space width (values represents shown as $\mathrm{m} \pm \mathrm{SEM}$ ).

To evaluate the therapeutic effect of CETH in simulated pathology, we focused on the width of the joint space, as there is data [49] that this value correlates with the thickness of cartilage. Changes in the joint space, expressed primarily in its narrowing, are an undeniable sign of rheumatoid arthritis. According to the results of Pfeil et al. [50] the X-ray computer assessment is a useful criterion in monitoring the progression of arthritis and therapeutic assessment.

The micro-CT images we received showed a significant narrowing of the joint space in Group II $(29.0 \%)$ compared to the healthy control group (Figure 2a,b,f). Micro-CTs of the ankle joint of animals receiving diclofenac, CETH $(60 \mathrm{mg} / \mathrm{kg})$, and CETH $(120 \mathrm{mg} / \mathrm{kg})$ show a marked increase in the width of joint space in comparison with the model group II by $31.8 \%, 20.5 \%$, and $38.6 \%$, respectively (Figures 2c,d,e,f). 
The introduction of adjuvant in the modeling of arthritis caused a marked loss of bone tissue and weakening of trabecular microarchitecture. In comparison with the group with simulated arthritis, the fragmentation of trabecular bone was detected in varying degrees (Figure 3).

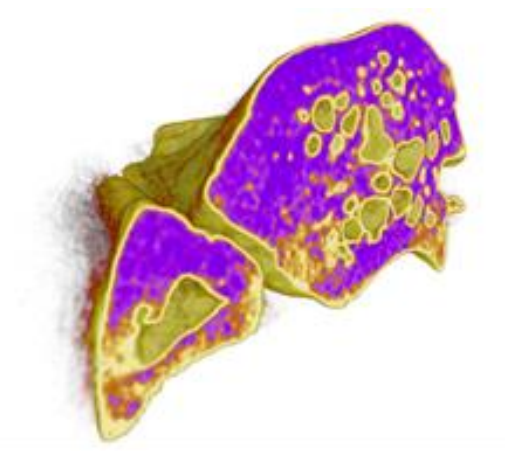

(a)

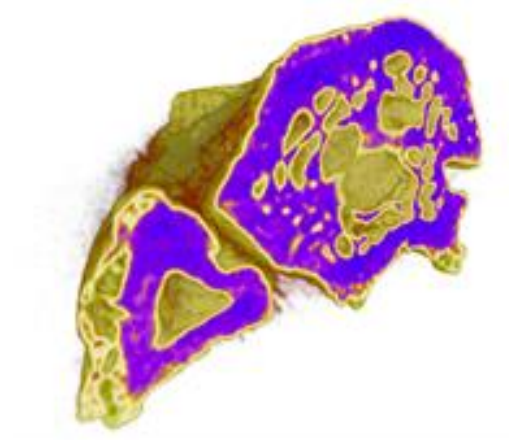

(d)

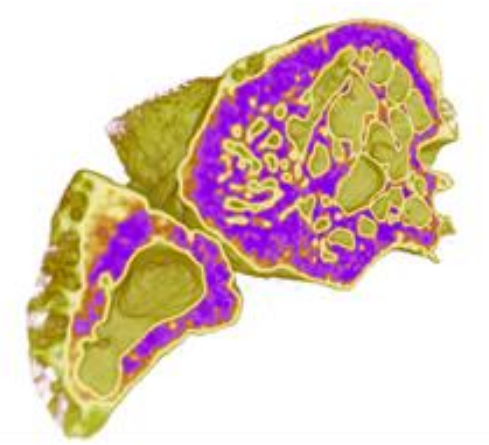

(b)

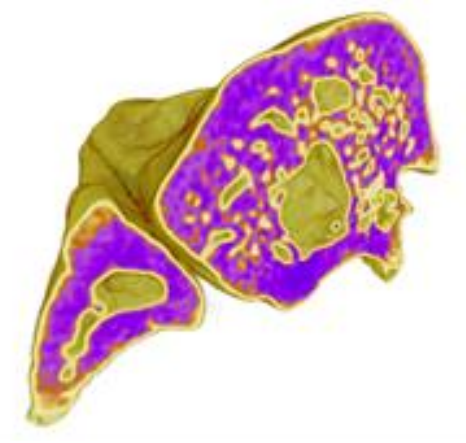

(e)

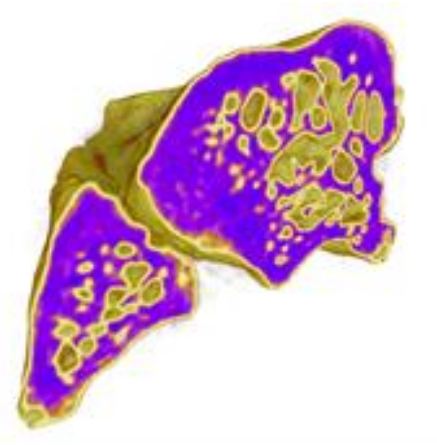

(c)

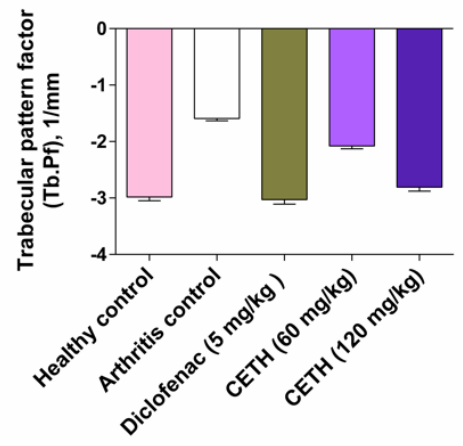

(f)

Figure 3. Periarticular bone resorption. Three-dimensional reconstructions of micro-CT images of the trabecular microarchitecture of the distal metaphysis of rat tibia. Transverse slice(a) Group I - healthy control; (b) Group II - arthritis control; (c) Group III - arthritis with Diclofenac sodium (5 mg/kg) treatment; (d) Group IV - arthritis with CETH $(60 \mathrm{mg} / \mathrm{kg}$ ) treatment; (e) Group V - arthritis with CETH $(120 \mathrm{mg} / \mathrm{kg}$ ) treatment; (f) Trabecular pattern factor (Tb. Pf), 1/mm (values represents shown as $\mathrm{m} \pm \mathrm{SEM})$.

According to 3D images in Group II, the tibia distal metaphysis was characterized by high porosity and loss of trabecular connections. A large proportion of bone trabeculars lost their normal architecture and looked like separate bone areas separated by extended spaces. This is consistent with the results of several researchers [47] and, according to Noguchi et al. [51] can be caused by activation of inflammation mediators, by means of which stimulation of osteoclastic formation takes place, which eventually leads to periarticular bone resorption [52].

Micro-CT images of the distal metaphysis of the tibia in rats of group III treated with Diclofenac (Figure 3c) and groups IV and V treated with CETH (Figure 3d,e) show the presence of a protective effect in relation to bone resorption. Group V animals had the largest effect. They still had areas of resorption, but the overall integrity of the trabecular architecture of the bone components of the joint, in particular the tibia, was as close to the group I as possible. This was quantitatively confirmed by reliable differences in the value of the trabecular pattern factor (Tb.Pf) (Figure 3f), reflecting the connectivity of bone structures and negatively correlating with bone strength [53].

The average value of TBPf in Group II almost twice exceeded this value in Control Group I. In groups III, IV, and V, a significant decrease of TBPf was observed in comparison with II. In sample III, which received diclofenac, TBPf decreased by $90.5 \%$. In groups IV and V, TBPf decreased by $30.8 \%$ and $76.7 \%$, respectively, compared to CETH. 
This and other quantitative parameters of the trabecular microarchitecture of subchondral bone, reproduced by three-dimensional microtomography analysis, are presented in Table 2.

Table 2. Microarchitecture parameters of tibia distal metaphysis by micro-CT analysis $(\mathrm{M} \pm \mathrm{m})$.

\begin{tabular}{cccccccc}
\hline Groups & $\begin{array}{c}\mathbf{1 B V} / \mathbf{T V}, \\
\mathbf{\%}\end{array}$ & $\begin{array}{c}{ }^{2} \mathbf{T b} . \mathbf{P f}, \\
\mathbf{1} / \mathbf{m m}\end{array}$ & $\begin{array}{c}{ }^{3} \mathbf{T b} . \mathbf{T h}, \\
\mathbf{m m}\end{array}$ & $\begin{array}{c}{ }^{4} \mathbf{T b} . \mathbf{S p}, \\
\mathbf{~ m m}\end{array}$ & $\begin{array}{c}{ }^{5} \mathbf{B S} / \mathbf{B V}, \\
\mathbf{1} / \mathbf{m m}\end{array}$ & $\begin{array}{c}{ }^{6} \mathbf{T b} . \mathbf{N}, \\
\mathbf{1 / m m}\end{array}$ & ${ }^{7} \mathbf{S M I}$ \\
\hline Healthy & 66.89 & $-2,98$ & 0.31 & 0.50 & 9.14 & 2.19 & -1.70 \\
control & $\pm 0.45^{\mathrm{a}}$ & $\pm 0.07^{\mathrm{a}}$ & $\pm 0.005^{\mathrm{a}}$ & $\pm 0.028^{\mathrm{a}}$ & $\pm 0.23^{\mathrm{a}}$ & $\pm 0.042^{\mathrm{a}}$ & $\pm 0.12^{\mathrm{a}}$ \\
Arthritic & 52.98 & -1.59 & 0.24 & 0.61 & 13.48 & 2.22 & -1.08 \\
control & $\pm 0.68^{\mathrm{b}}$ & $\pm 0.04^{\mathrm{b}}$ & $\pm 0.003^{\mathrm{b}}$ & $\pm 0.036^{\mathrm{b}}$ & $\pm 0.34^{\mathrm{b}}$ & $\pm 0.050^{\mathrm{a}}$ & $\pm 0.19^{\mathrm{b}}$ \\
Diclofenac & 59.46 & -3.03 & 0.24 & 0.49 & 11.96 & 2.44 & -1.34 \\
$(5 \mathrm{mg} / \mathrm{kg})$ & $\pm 0.56^{\mathrm{b}}$ & $\pm 0.08^{\mathrm{a}}$ & $\pm 0.005^{\mathrm{b}}$ & $\pm 0.051^{\mathrm{a}}$ & $\pm 0.41^{\mathrm{c}}$ & $\pm 0.039^{\mathrm{a}}$ & $\pm 0.15^{\mathrm{c}}$ \\
CETH & 62.78 & -2.08 & 0.28 & 0.55 & $12.06^{\mathrm{c}}$ & 2.35 & -1.66 \\
$(60 \mathrm{mg} / \mathrm{kg})$ & $\pm 1.86^{\mathrm{a}}$ & $\pm 0.05^{\mathrm{c}}$ & $\pm 0.004^{\mathrm{c}}$ & $\pm 0.027^{\mathrm{a}}$ & \pm 0.29 & $\pm 0.049^{\mathrm{a}}$ & $\pm 0.27^{\mathrm{a}}$ \\
CETH & 69.90 & -2.81 & 0.27 & 0.52 & 11.27 & 2.58 & -1.75 \\
$(120 \mathrm{mg} / \mathrm{kg})$ & $\pm 1.41^{\mathrm{a}}$ & $\pm 0.07^{\mathrm{a}}$ & $\pm 0.007^{\mathrm{c}}$ & $\pm 0.065^{\mathrm{c}}$ & $\pm 0.31^{\mathrm{c}}$ & $\pm 0.073^{\mathrm{a}}$ & $\pm 0.18^{\mathrm{a}}$ \\
\hline
\end{tabular}

Different superscript letters indicate statistically significant differences between the means $(\mathrm{P}<0.05)$ for each parameter. ${ }^{1}$ Percent bone volume; ${ }^{2}$ Trabecular pattern factor; ${ }^{3}$ Trabecular thickness;

${ }^{4}$ Trabecular separation; ${ }^{5}$ Bone surface/bone volume; ${ }^{6}$ Trabecular number; ${ }^{7}$ Structure model index.

The BV/TV ratio as a predictor of bone strength in Group II was $20.8 \%$ lower than in Group I. Groups IV and V that received CETH were characterized by $18.5 \%$ and $31.9 \%$ increase in BV/TV compared to Group II, respectively. The use of Diclofenac in Group III did not statistically affect the value of $\mathrm{BV} / \mathrm{TV}$.

The values of Tb.N parameter in accordance with Kim \& Kang's data [54] did not undergo statistically significant changes after the modeling of arthritis. This is probably due to the fact that the main bone loss in the periarticular zones was not due to the perforation of bone trabeculae, as is often observed in osteoporosis [55], but due to the thinning of trabeculae. This is confirmed by the changes in $\mathrm{Tb}$.Th. values we have detected.

The data on group distribution of the parameter $\mathrm{Tb}$.Th, which is one of the criteria for osteoanabolic action, was presented interestingly. Group II was characterized by a reliable decrease in Tb.Th value in comparison with the control. The application of Diclofenac in Group III did not affect $\mathrm{Tb}$.Th values, and it remained as low as in Group II. At the same time, groups IV and V after the application of CETH showed a significant increase in the Tb.Th value in comparison with group II but remained low in relation to the Tb.Th values of group I of healthy controls.

The value of SMI, reflecting the loss of bone strength, in the model group, II increased by $36.5 \%$ compared to the control. Against the background of diclofenac application in group III, this index reliably decreased by $24.1 \%$. The downward changes in SMI compared to the model group II in samples IV and V were $53.7 \%$ and $62.0 \%$, respectively.

Group II was characterized by relatively high values of Tb.Sp. and BS/BV. These changes are another confirmation of bone mass loss, and according to Kim \& Kang [54] a quantitative sign indicating the formation of osteophytes.

In this study, following the study provided by Kim \& Kang [54], osteophytes were visualized using CTvox and CTvol software (Bruker-microCT, Belgium) (Figure 4). In 3D images, they are represented as blue colored outgrowths with an uneven surface formed along the edges of joints and bones. 


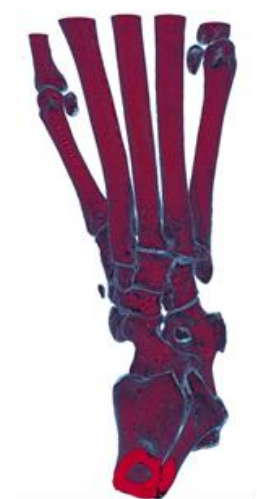

(a)

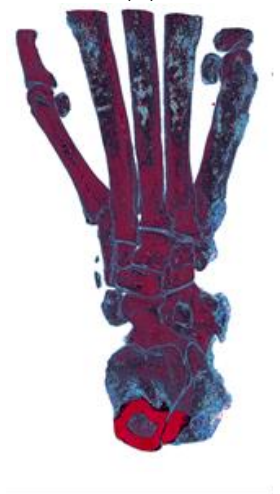

(d)

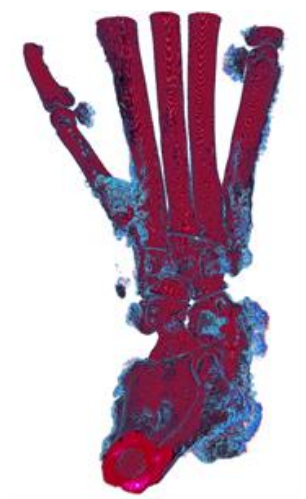

(b)

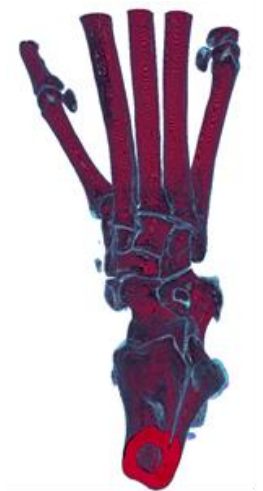

(e)

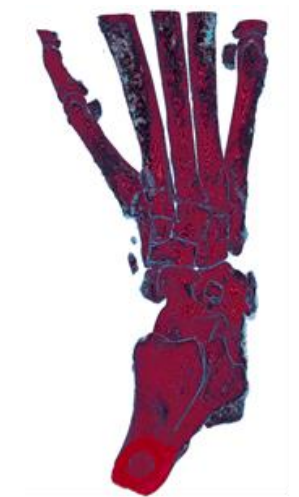

(c)

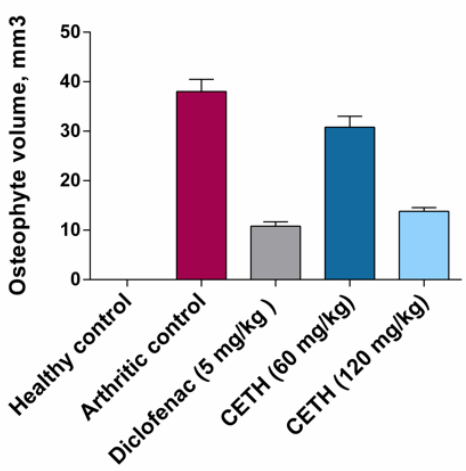

(f)

Figure 4. Visualization of osteophytes on three-dimensional micro-CT images of rat paw skeleton(a) Group I healthy control; (b) Group II - arthritis control; (c) Group III - arthritis with Diclofenac sodium (5 mg/kg) treatment; (d) Group IV - arthritis with CETH (60 mg/kg) treatment; (e) Group V - arthritis with CETH (120 $\mathrm{mg} / \mathrm{kg}$ ) treatment; (f) Osteophyte volume, $\mathrm{mm}^{3}$ (values represents shown as $\mathrm{m} \pm \mathrm{SEM}$ ).

According to micro-CT data, all groups of animals with induced arthritis were accompanied by osteophytosis. These pathomorphological changes are typical not only for osteoarthritis but also often occur in the development of adjuvant arthritis, which has been repeatedly confirmed in the works of other researchers $[47,56]$.

The quantitative volumetric characteristics of osteoarthritis obtained differed greatly among the groups of animals studied. Osteophytes were not registered in animals of control group I (Figure 4, a). The maximum volume of osteophytes formed was characterized by group II (Figure 4,b). Oral administration of Diclofenac rats $(5 \mathrm{mg} / \mathrm{kg}$ ) and CETH $(60$ and $120 \mathrm{mg} / \mathrm{kg}$ ) significantly prevented osteophytes development (Figure 4c,d,e). The effectiveness of CETH in a dose of $120 \mathrm{mg} / \mathrm{kg}$ was comparable to that of diclofenac (Figure $4 \mathrm{f}$ ). This is confirmed by the above values of BS/BV and $\mathrm{Tb} . \mathrm{Sp}$, which in groups III, IV, and V were significantly lower than in the model group II.

\subsection{Histopathological analysis}

Since the possibilities of micro-CT analysis to study cartilage structures are somewhat limited, histological analysis of the joint tissues of the white rat ankle was performed to evaluate the effectiveness of CETH anti-arthritic action.

According to the results of the histological study, no inflammation or tissue destruction was observed in Group I. In groups II, III, IV, and V, pathomorphological signs characteristic for adjuvant arthritis of various degrees of severity were found.

In all animals of group II, during the histological analysis of an ankle joint, pronounced changes in bone tissue were found, in particular, trabecular osteolysis. In group II, the average 
semi-quantitative calculation of the level of bone tissue changes in the joint area was $3.2 \pm 0.08$ (Figure 5b,f).

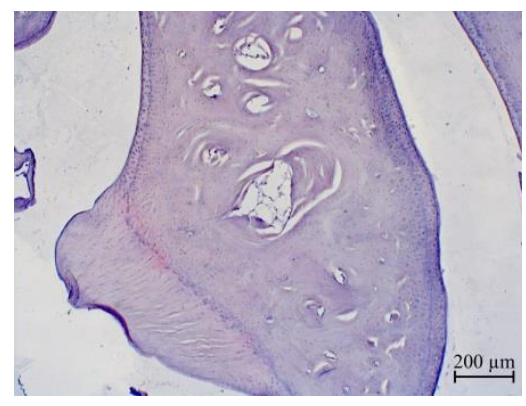

(a)

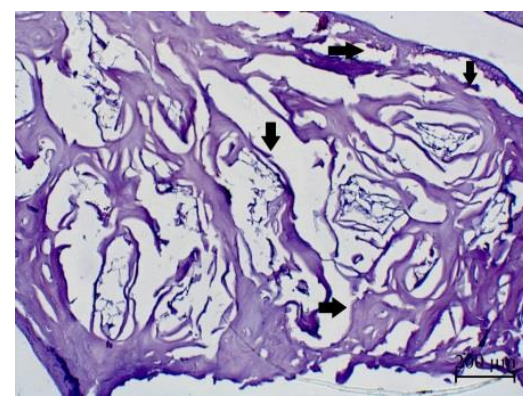

(d)

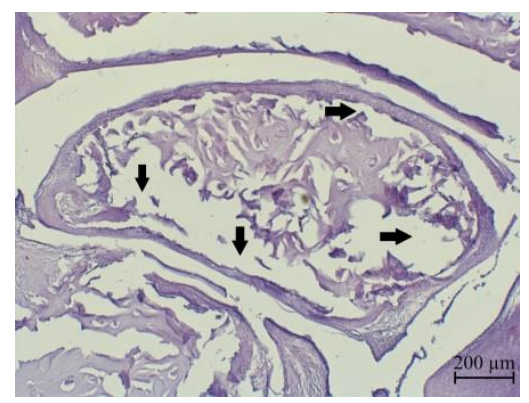

(b)

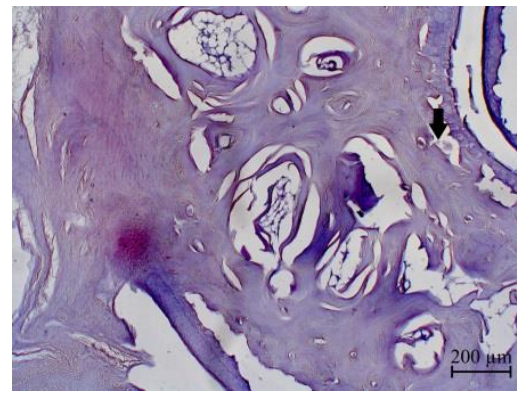

(e)

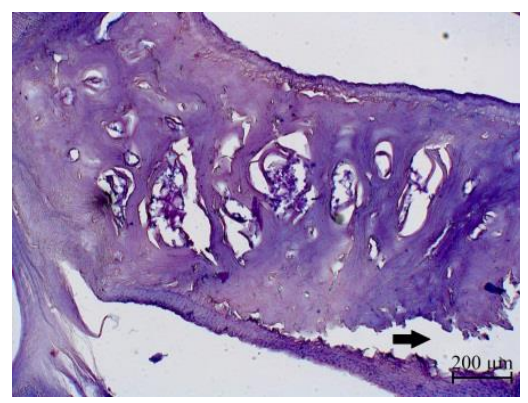

(c)

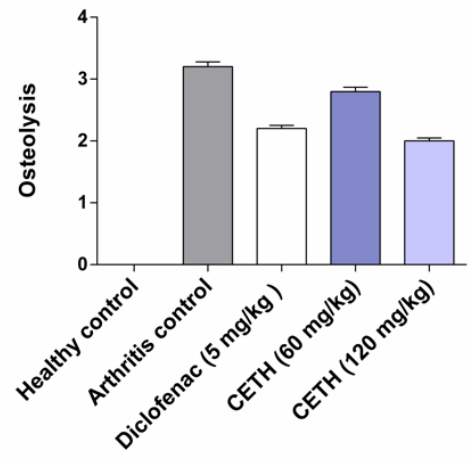

$(\mathbf{f})$

Figure 5. The condition of the ankle bone of the rats. Coloring with hematoxylin and eosin, $\times 50:(a)$ Group I - healthy control. Joint surfaces, chondrocytes are normal (indicated by arrows); (b) Group II - arthritis control. Joint surfaces with signs of dystrophic and necrotic chondrocyte lesions (indicated by arrows); (c) Group III - arthritis with Diclofenac sodium (5 mg/kg) treatment. Joint surfaces with irregularities (indicated by an arrow); (d) Group IV - arthritis with CETH $(60 \mathrm{mg} / \mathrm{kg}$ ) treatment. Joint surfaces with irregularities and curved groups of 2 cells (indicated by the arrow); (e) Group V arthritis with CETH $(120 \mathrm{mg} / \mathrm{kg})$ treatment. Joint surfaces with irregularities, small cracks (indicated by arrow); (f) Degree of cartilage damage (values represents as $\mathrm{m} \pm \mathrm{SEM}$ ).

In groups III, IV, and V, histological analysis of bone tissue changes showed less pronounced osteolysis. These groups were characterized by a much lower degree of resorption of the medullary tibia region. In ankle bone, the weak level of trabecula resorption was visualized in the animals of group IV, who received CETH $60 \mathrm{mg} / \mathrm{kg}$, then in group II (Figure $5 \mathrm{~d}$ ). In the samples of animals III and V, for which diclofenac $5 \mathrm{mg} / \mathrm{kg}$ and CETH $120 \mathrm{mg} / \mathrm{kg}$ were used, respectively, the histological picture of the named bones was approaching the norm (Figure 5c,e).

A semi-quantitative calculation of the severity of changes in bone tissue from all visualized bones forming the ankle joint indicates that the osteolysis level in animals using CETH at $120 \mathrm{mg} / \mathrm{kg}$ was $10 \%$ lower than with diclofenac and $37.5 \%$ lower than in animals with negative control II (Figure 5f).

In the ankle joint of animals of group II, hyperplasia of cells of synovial shell and its thickening and the presence of dark bulbous villi on synovial intima was observed. Significant signs of inflammatory reaction in periarticular tissues with increased vascularization, swelling, infiltration of inflammatory cells were registered (Figure 6b).

The average semi-quantitative calculation of joint inflammation severity for Group II was $3.9 \pm$ 0.1 (Figure 6f). 


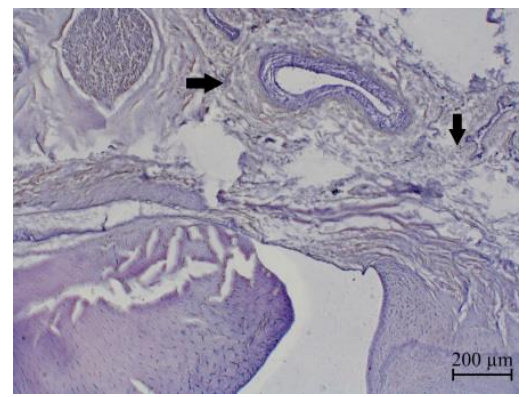

(a)

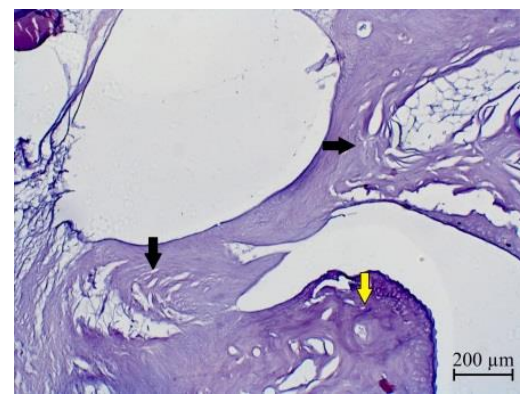

(d)

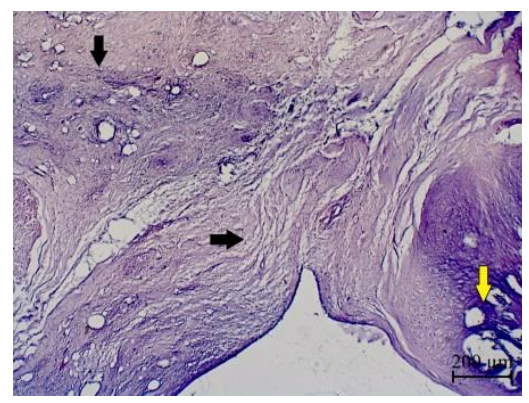

(b)

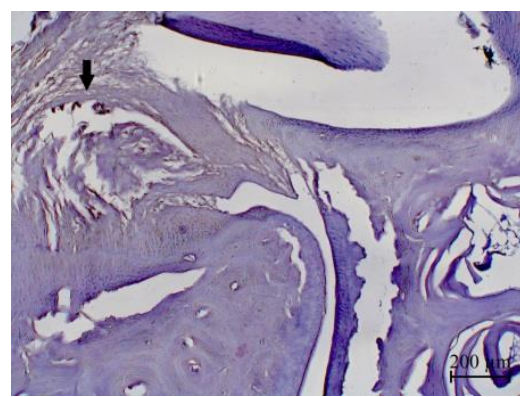

(e)

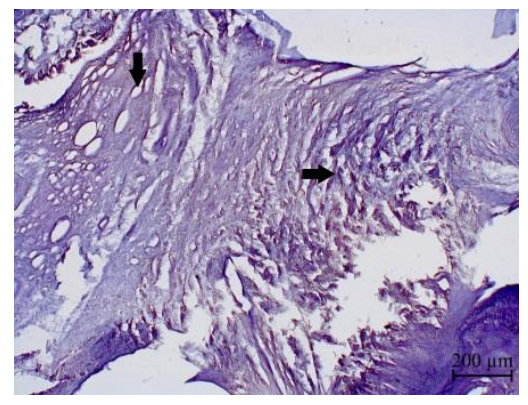

(c)

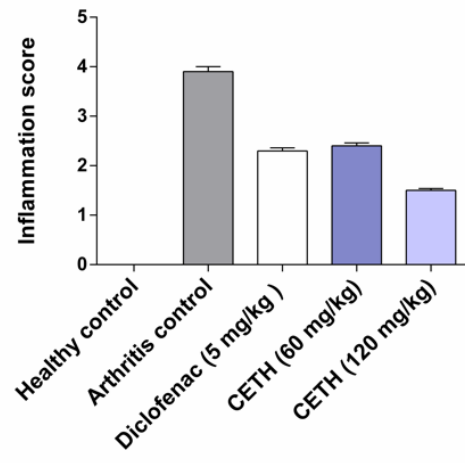

(f)

Figure 6. State of periarticular tissues. Coloring with hematoxylin and eosin, $\times 50$ : (a) Group I - healthy control. Periarticular tissues are normal (indicated by arrows); (b) Group II - arthritis control. Significant thickening and signs of marked inflammatory reaction in periarticular tissues (indicated by arrows), osteophyte (yellow arrow); (c) Group III - arthritis with Diclofenac sodium (5 mg/kg) treatment. Mild infiltration with moderate swelling in periarticular tissues (indicated by the arrows); (d) Group IV - arthritis with CETH (60 $\mathrm{mg} / \mathrm{kg}$ ) treatment. Mild periarticular infiltration with mild swelling (indicated by the arrows), slight osteophyte (yellow arrow); (e) Group V - arthritis with CETH $(120 \mathrm{mg} / \mathrm{kg})$ treatment. Mild periarticular tissue infiltration (indicated by the arrow); (f) General joint inflammation expression (values shown as $\mathrm{m} \pm \mathrm{SEM}$ ).

In all experimental groups with the use of drugs, the inflammatory response in periarticular tissues was characterized by a much lower level than in animals without treatment. In groups using diclofenac and peptides in the dose of $60 \mathrm{mg} / \mathrm{kg}$, the manifestations ranged from mild to moderate infiltration by inflammatory cells with moderate swelling (Figure 6c,d). The lowest level of general joint inflammation was characterized by animals of group V receiving CETH $120 \mathrm{mg} / \mathrm{kg}$ (Figure 6e). In a semi-quantitative calculation, their average inflammation rate was $1.5 \pm 0.05$, which was 35\% less than in animals after the application of Diclofenac $5 \mathrm{mg} / \mathrm{kg}$ and $37 \%$ less than in animals with CETH $60 \mathrm{mg} / \mathrm{kg}$. No reliable difference between histological changes in rat periarticular tissues after diclofenac $5 \mathrm{mg} / \mathrm{kg}$ and CETH $60 \mathrm{mg} / \mathrm{kg}$ was found $(2.3 \pm 0.06$ and $2.4 \pm 0.07$, respectively) (Figure 6f).

The degree of cartilage degeneration in Group II was the most pronounced and was characterized by swelling and vacuumization of the matrix, the development of dystrophic and necrotic lesions of chondrocytes. Surface erosions and splits were found in cartilage tissue. In severe cases, there was thinning and impoverishment of cartilage tissue cells, with proliferation foci, there were found out curved groups of chondrocytes of 2,3 , and more cells. The degeneration of cartilage was $6.1 \pm 0.15$ points. 


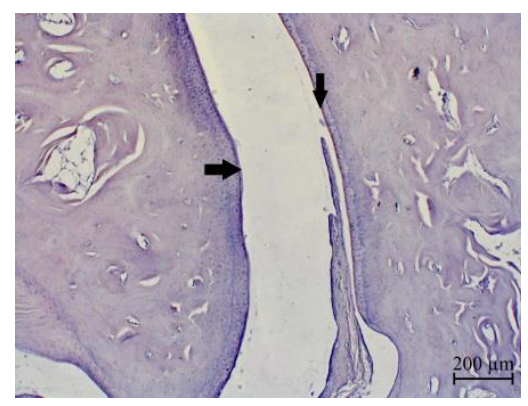

(a)

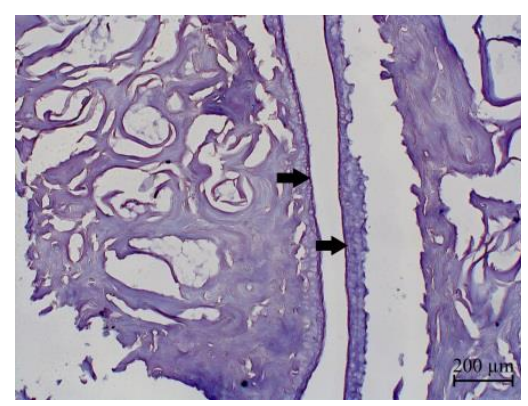

(d)

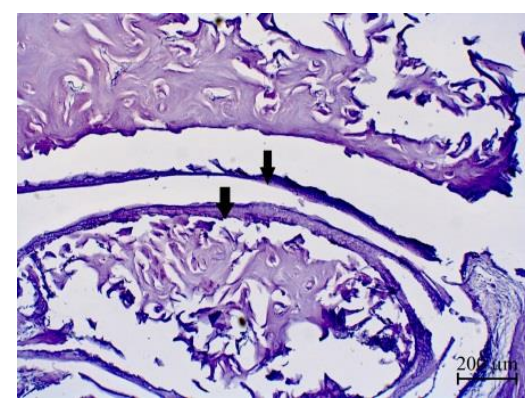

(b)

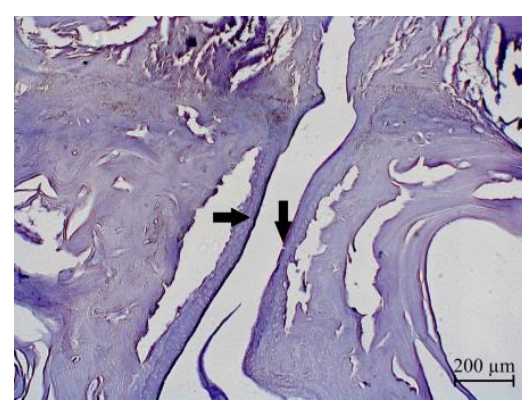

(e)

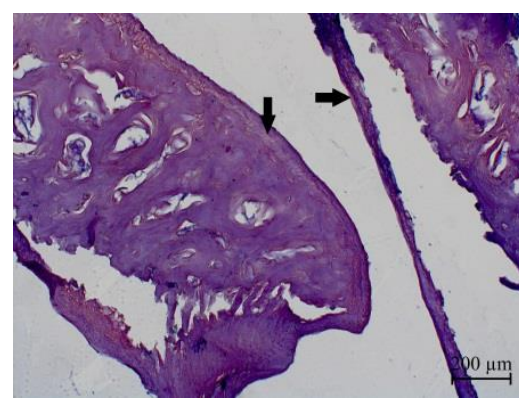

(c)

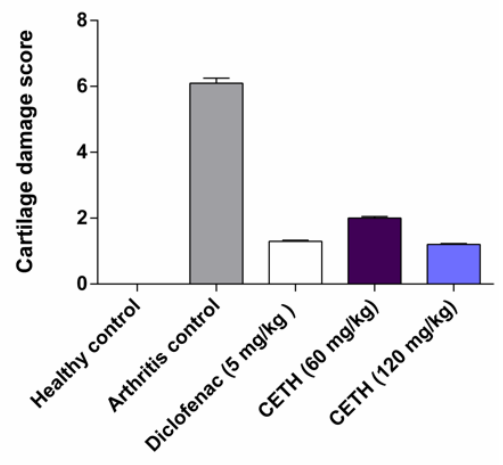

(f)

Figure 7. The condition of cartilage tissue of the joint. Coloring with hematoxylin and eosin, $\times 50$ : (a) Group I healthy control. Joint surfaces, chondrocytes are normal (indicated by arrows); (b) Group II - arthritis control. Joint surfaces with signs of dystrophic and necrotic chondrocyte lesions (indicated by arrows); (c) Group III arthritis with Diclofenac sodium $(5 \mathrm{mg} / \mathrm{kg}$ ) treatment. Joint surfaces with irregularities (indicated by an arrow); (d) Group IV - arthritis with CETH $(60 \mathrm{mg} / \mathrm{kg})$ treatment. Joint surfaces with irregularities and curved groups of 2 cells (indicated by the arrow); (e) Group V - arthritis with CETH (120 mg/kg) treatment. Joint surfaces with irregularities, small cracks (indicated by arrow); (f) Degree of cartilage damage (values represents as $\mathrm{m} \pm \mathrm{SEM}$ ).

Histological evaluation of the degree of cartilage tissue degeneration in the region of ankle joints in animals of groups III and V indicates small irregularities, erosions, and some animals have cracks. In the groups of animals, which used diclofenac $5 \mathrm{mg} / \mathrm{kg}$ and CETH $120 \mathrm{mg} / \mathrm{kg}$, there were practically no changes on the part of chondrocytes. There were also no reliable differences in the semi-quantitative calculation of cartilage damage (1.3 \pm 0.04 and $1.2 \pm 0.03$ points, respectively). When using CETH $60 \mathrm{mg} / \mathrm{kg}$ in animals, IV showed more pronounced histological changes in the joints, which were characterized not only by irregularities and erosions but also by the presence of corrugated groups of chondrocytes with two cells in a group. The degree of cartilage degeneration in this group was $2.0 \pm 0.05$ points.

\subsection{Immunohistochemistry analysis}

In addition to histological analysis using the immunohistochemical method, the level of expression of caspase- 3 was assessed as an indicator of cell death of synovial joint membrane cells.

In the group of animals of healthy controls, a weak, almost absent staining of the caspase- 3 synovial membrane was observed, which was quantitatively confirmed by the minimum optical density indicator (Figure 8a,f). 


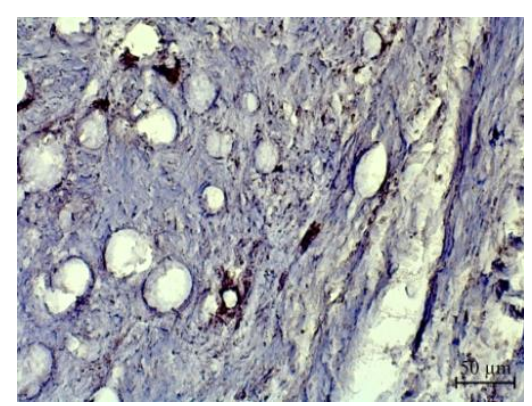

(a)

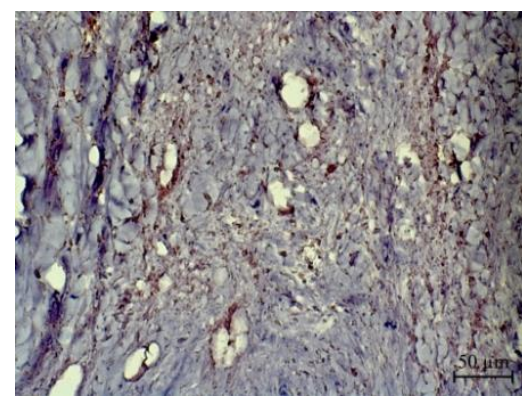

(d)

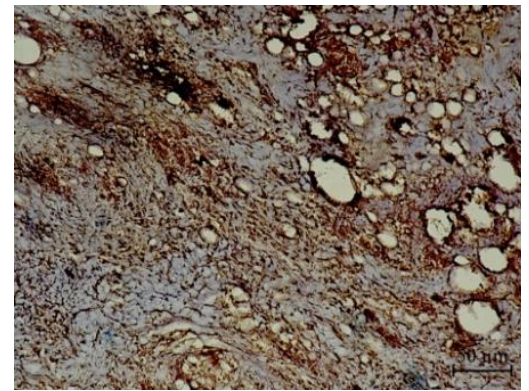

(b)

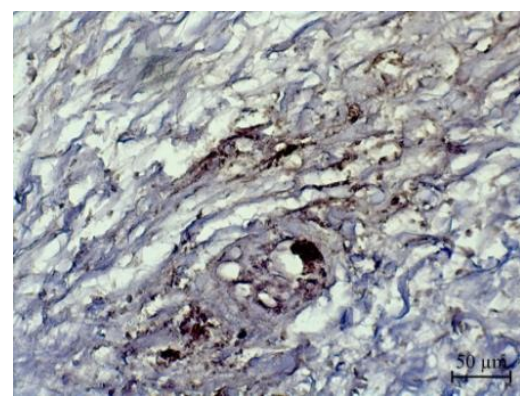

(e)

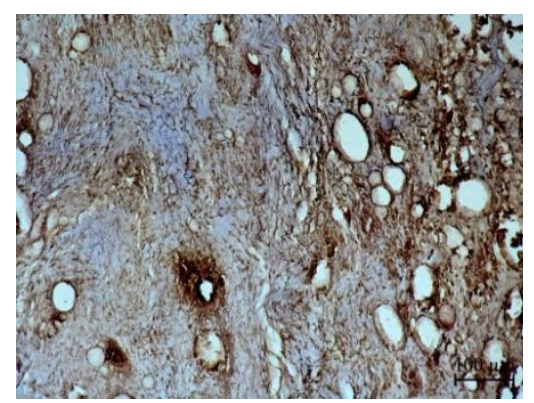

(c)

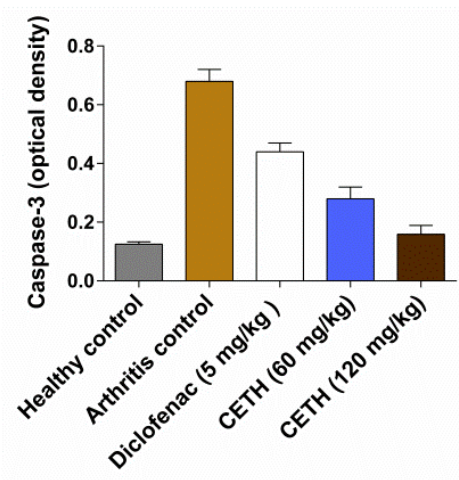

(f)

Figure 8: Immunohistochemical expression of caspase- 3 in the synovial membrane of the rat ankle in adjuvant arthritis on day 28, ×200: (a) Group I - healthy control. Weak expression of caspase-3; (b) Group II - arthritis control. Super strong expression of caspase-3; (c) Group III - arthritis with Diclofenac sodium (5 mg/kg) treatment. Strong expression of caspase-3; (d) Group IV - arthritis with CETH $(60 \mathrm{mg} / \mathrm{kg}$ ) treatment. Moderate expression of caspase-3; (e) Group V - arthritis with CETH $(120 \mathrm{mg} / \mathrm{kg}$ ) treatment. Weak expression of caspase-3; (f) Caspase-3 expression quantification, expressed as optical density (values represents shown as $\mathrm{m} \pm \mathrm{SEM}$ ).

Model Group II was characterized by high expression of caspase-3, as evidenced by intensive brown coloring (Figure 8b). In agreement with the recently obtained results of Shafiey et al. [57] and Abdel-Maged et al. [58], it is logically explained that apoptosis may be one of the mechanisms of progression of rheumatoid arthritis due to the activation of proapoptotic proteins like caspase-3.

In groups of animals, where diclofenac sodium and CETH were used, on day 28, models of adjuvant arthritis were characterized by less pronounced expression of caspase-3 (Fig. 8c,d,e). In the order of its reduction and accordance with the results of the average optical density of images, the groups were distributed as follows: group III > group IV > group V (Figure 8f). This pattern of caspase-3 expression showing the level of apoptosis in periarticular tissues also confirms the decrease of inflammatory alteration in these groups.

\section{Discussion}

Alternatives to control rheumatoid arthritis are becoming increasingly popular $[17,20,59,60]$. With progress in the understanding of the pathophysiology and treatment of rheumatoid arthritis, it has been proven that its nutritional correction is realistic. Dietary approaches can serve as an effective strategy for improving rheumatoid arthritis [61-63].

Of particular interest in this respect are bioactive peptides and peptide-rich protein hydrolysates, which represent a new trend in the development of functional foods and nutraceuticals [64,65].

The chicken embryo tissue hydrolysate (CETH) we are studying has an interesting representation and ratio of oligopeptides and free amino acids with different bioactivity [38]. Therefore, CETH has a promising therapeutic potential for use in pharmacology and nutraceuticals. However, this requires multidirectional experimental validation. 
In this study, we have sought to assess the anti-arthritic effect of CETH. Hatori et al. [66] studied the anti-arthritic effect of casein hydrolyzate without dividing it into components; however, we evaluated the peptide-amino acid mixture of CETH to assess the complex action of all its components.

On in vitro models, CETH exhibited concentration-dependent inhibition of protein denaturation, membrane stabilization effect, and inhibitory proteinase activity.

Most researchers report that protein denaturation is one of the reasons for rheumatoid arthritis development due to autoantigen production [67]. The expressed property of CETH to block the denaturation of protein even exceeding the NSAID (sodium diclofenac) activity revealed in this study allows us to assert the potential control of the CETH production of autoantigens in rheumatic states.

The stabilizing effect on erythrocyte lysis caused by a hypotonic medium is also a criterion of anti-arthritic activity. The erythrocyte membrane is similar to the lysosomal membrane, whose stabilization during the inflammatory process prevents the release of lysosomal enzymes of activated neutrophils, which lead to inflammation progression and tissue damage. One such enzyme of lysosomal granules is proteinases, which enzymatically destroys collagen and proteoglycan matrix of bones and cartilages [45]. Although the exact mechanisms of membrane protection and inhibition of CETH proteinase are not yet known, it has shown quite a high effect.

The results obtained in vitro prompted us to evaluate the advantages of CETH ex vivo on the animal model for its harmlessness and efficiency.

CETH did not show toxicity in experimental rats, which allowed us to consider it safe for further study on animals.

A model of chronic adjuvant inflammation was used, which is a classic to study the efficacy of anti-arthritic drugs. Swelling, inflammatory cell infiltrations, proliferative synovitis, and bone and cartilage structure erosion are clinical signs common to human rheumatoid arthritis and adjuvant-induced arthritis in rats [51,68].

Taking into account that the most reliable methods of assessing the impact of any factors on the body are deservedly considered morphological, and also taking into account that the indicators of the progression of rheumatoid arthritis are radiological and histopathological changes, the anti-arthritic effect of CETH has been studied by X-ray microtomography and histopathological analysis.

The study showed that oral administration of CETH to rats weakened arthritis progression and provided effective dose-dependent correction of morphological changes caused by the adjuvant injection.

Moreover, we compared CETH with the traditional NSAID rheumatoid arthritis treatment with sodium diclofenac. The use of CETH has shown relatively high recovery effects in terms of reduced inflammatory edema, osteolysis inhibition, osteophitosis prevention, periarticular tissue inflammatory response, and cartilage degeneration.

According to the complex of all morphological data obtained by X-ray micro-CT and histopathological analysis of the injected leg, the progression of adjuvant arthritis in rats is effectively controlled by CETH treatment $(120 \mathrm{mg} / \mathrm{kg})$.

Several mechanisms can logically be assumed to provide the detected effect. In addition to the mechanisms we have registered in vitro, one of the supposed mechanisms of morphologically confirmed anti-arthritic effect of CETH may be antioxidant. The role of antioxidants in rheumatoid arthritis therapy has been confirmed by many researchers $[69,70]$. The oxidative stress that occurs in an inflamed joint and the decrease in the antioxidant status of the body are the hallmarks of rheumatoid arthritis patients. They contribute to the development of the autoimmune process, lead to the degradation of connective tissue leading to deformation of the joints and periarticular tissues [71, 72].

In addition, active oxygen forms that increase in the late stages of arthritis lead to the induction of synoviocyte and chondrocyte apoptosis [73]. 
Previously, we registered a high antioxidant activity of CETH, particularly ABTS radical scavenging activity and lipid peroxidation inhibition activity [38].

Another suggested mechanism of the CETH anti-arthritic effect could be provided by bioactive low molecular weight peptides. According to our early studies, CETH contains various di- and tripeptides, including the dipeptide proline hydroxyproline (Pro-Hyp) [38].

According to Lee et al. [74], Pro-Hyp dipeptides inhibit chondrocyte loss and thinning of articular cartilage caused by the pathology. CETH Hyp can act as a signal for chondrocyte differentiation, thus providing protection for joint cartilage.

We believe that the anti-arthritic effect of CETH does not exclude the role of natural carnosine and arsenin dipeptides. According to Drafi et al. [75] carnosine inhibits the degradation of hyaluronic acid caused by free-radical processes and corrects the redox imbalance in adjuvant arthritis. In addition, according to Ponist et al. [76] carnosine may have a systemic anti-inflammatory effect in experimental arthritis.

There is evidence that supplements of dipeptide anserin help reduce inflammatory markers in rats with rheumatoid arthritis [77].

According to our recent results, the carnosine and arsenin content of CETH is $490.3 \pm 12.3$ and $24.5 \pm 0.6 \mu \mathrm{g} / \mathrm{ml}$, respectively [38].

We also believe that the therapeutic efficacy of CETH may be due to the functional peptides of GRKP and QPTIPFFDPQIPK sequences identified by us in its composition [38], whose immunomodulatory properties have been repeatedly noted in the literature $[78,79]$.

In addition, the morphologically proven anti-arthritic effect of CETH after oral administration can also be provided by its constituent peptides possessing dipeptidyl peptidase IV (DPP IV) inhibitor activity. According to some reports, DPP IV inhibitors can inhibit the progression of rheumatoid arthritis in animal models by inhibiting the proliferation of T-lymphocytes [80,81]. It is believed that DPP IV on activated T cells is a target molecule for rheumatoid arthritis therapy [82]. However, it is noteworthy that, according to Huang et al. [83] some peptides possessing dipeptidyl peptidase IV (DPP IV) inhibitor activity successfully pass through the gastrointestinal tract with the preservation and even increase of this property.

According to our earlier peptide analysis [38], CETH includes seven short-chain peptides with dipeptidyl peptidase IV inhibitor activity.

The osteoanabolic role of bioactive peptides cannot be ruled out in the detected effect of CETH. According to Amso et al. [84] and Mada et al. [85], individual short food peptides can reduce the expression of inflammatory and resorbing cytokines and stimulate differentiation of osteoblasts by increasing the expression of osteogenic genes and the activity of antioxidant enzymes.

Under the conditions of the adjuvant arthritis model used, CETH showed a good osteo-anabolic result, which indicates its high potential as an effective strategy in maintaining and correcting bone homeostasis in states characterized by pronounced bone resorption.

Another important factor in ensuring the anti-arthritic effect of CETH on chronic arthritis models can be considered as the effect on apoptosis. Apoptosis is regarded as one of the mechanisms involved in the regulation of rheumatoid arthritis. Its role is dual and depends on the stage of arthritis development [86].

The early stages of adjuvant arthritis are characterized by insufficient apoptosis. Starting from the 23rd day, the late-stage is characterized by apoptosis activation of synoviocytes and chondrocytes [73].

In our study, it would be logical to assume the apoptosis-inducing activity of $\mathrm{CETH}$, which could be provided by bioactive peptides of embryonic tissue that induce apoptosis processes actively occurring in embryogenesis. An example is the carnosine dipeptide contained in high amounts in CETH, which, according to Pandurangan et al. $[87,88]$ has a pronounced apoptosis-inducing effect due to inhibition of caspase activity -3 .

However, the current immunohistochemical results for 28 days of the model of adjuvant arthritis in rats indicate overwhelming apoptosis of CETH activity. This may be due to possible non-peptide inhibitors of caspase -3 contained in CETH and new bioactive peptides formed as a 
result of hydrolysis. Besides, the recorded level of apoptosis in periarticular tissues with CETH may be due to a marked decrease in the level of inflammatory alteration, which was recorded by us in the histochemical study. This once again confirms the need for further research to isolate pure compounds from the CETH peptide-amino acid complex and to understand better all the mechanisms involved in its anti-arthritic effect.

\section{Materials and Methods}

\subsection{Drugs and chemicals}

Chemicals were obtained from the following sources: pepsin from porcine gastric mucosa (activity 600-1800 U/mg), hydrochloric acid 35\% (Sigma-Aldrich, St. Louis, MI, USA); pancreatin (activity): amylase 22,500 FIP E/g, lipase 22,500 FIP E/g, protease $1050 \mathrm{FIP} \mathrm{E/g,} \mathrm{(AppliChem,}$ Darmstadt, Germany); bile extract, perchloric acid 70\%, casein from bovine milk, erypsin from bovine pancreas $\geq 10,000$ BAEE units/mg protein, formalin solution, neutral buffered $10 \%$, isopropyl alcohol $\geq 99.7 \%$ (Sigma-Aldrich, St. Louis, MI, USA); Adjuvant complete Freund (Difco Laboratories, Detroit, USA); Diclofenac sodium (AMOLI ORGANICS Private Limited, Mumbai, India).

\subsection{Materials}

Certified fertilized chicken eggs were produced by white Leggorn breeds of Kumskaya poultry (Georgievsk, Russia) set. Cultivation of embryos up to 10 days of age was carried out under laboratory conditions in an incubator ILB-0.5 (Russia) with automatic regulation of incubation parameters. During the incubation, the viability and level of embryos development were monitored using the PKYA-10 ovoscope (Moscow, Russia). In accordance with the patent of the Russian Federation No 2560845 [81], stimulation of embryos development was carried out using the AL-01 Semicon (Moscow, Russia) medical semiconductor laser device. On the 10th day of incubation, eggs with developed embryos were placed for 7 days in a refrigerator at $2-6^{\circ} \mathrm{C}$. The embryonic and extraembryonic tissues were then separated from the shell and ground using a Sterilmixer 12 knife homogenizer (PBI, Milan, Italy). The obtained substance was dried in a laboratory lyophilic dryer LS-500 (Russia) and stored at $20^{\circ} \mathrm{C}$ until use.

\subsection{Preparation of chicken embryo tissue hydrolysate (CETH)}

The raw material was a sublimated embryonic-egg mass from which the lipid fraction was removed by 5 -fold extraction with petroleum ether. It was stirred at $500 \mathrm{rpm}$ on the magnetic stirrer (Heildoph, Germany), followed by drying of the defatted residue at $37^{\circ} \mathrm{C}$ in an ES 20/60 thermoshaker (Biosan, Latvia). The resulting sublimate was carefully ground to a powdery state.

Five hundred $\mathrm{mL}$ of distilled water (DW) was mixed with $20 \mathrm{~g}$ of a sublimate and put into an ES 20/60 shaker-thermostat for 30 minutes at $50^{\circ} \mathrm{C}$. Then, $35 \% \mathrm{HCl}$ was added to the solution to a concentration of $0.5 \%$ and held at $50^{\circ} \mathrm{C}$ for 60 minutes with shaking $100 \mathrm{rpm}$ in an ES 20/60 shaker-thermostat. The resulting mass was then autoclaved at $125^{\circ} \mathrm{C}$ for 60 minutes in the SPVA-75-1NN steam sterilizer. Pancreatin $(2 \mathrm{mg} / \mathrm{mL})$ was added to a cooled substance, and the mixture was incubated in an ES 20/60 shaker-thermostat for 120 minutes at $37^{\circ} \mathrm{C}$ [38].

\subsection{In-vitro anti-arthritic activity:}

\subsection{1. inhibition of protein denaturation}

The study was conducted according to the methodology presented in the work of Niazi et al. [90]. The reaction mixture $(5 \mathrm{ml})$ consisted of $0.2 \mathrm{ml}$ of fresh egg albumin, $2.8 \mathrm{ml}$ of phosphate-salt buffer (pH 6.3), plus $2.0 \mathrm{ml}$ of different concentrations $(3.75,7.5,15.0 \mathrm{mg} / \mathrm{ml})$ of CETH. The same volume of bidistilled water was controlled. The reaction mixtures were incubated at $37^{\circ} \mathrm{C}$ for 15 minutes and then heated at $70^{\circ} \mathrm{C}$ for 5 minutes. After cooling, the absorption was measured at $660 \mathrm{~nm}$ with UV spectrophotometer SF 102 (NPO INTERFOTOFIZIKA, Moscow, Russia). The percentage of protein denaturation inhibition was calculated using the following formula: 


$$
\text { Percentage of inhibition }(\%)=\frac{\text { Abs control }- \text { Abs sample }}{\text { Abs control }} \times 100
$$

\subsubsection{Proteinase inhibitory action}

The analysis was performed according to the methodology described by Chandra et al. [67] with some modifications. The reaction mixture of $2.0 \mathrm{ml}$ included $250 \mu \mathrm{l}$ trypsin, $1.0 \mathrm{ml} 25 \mathrm{mM} \mathrm{Tris-} \mathrm{HCl}$ buffer $(\mathrm{pH} 7.4)$ and $1.0 \mathrm{ml}$ of different concentrations $(3.75,7.5,15.0 \mathrm{mg} / \mathrm{ml})$ of CETH. The same volume of bidistilled water was controlled. The mixture was incubated at $37^{\circ} \mathrm{C}$ for 5 minutes. $1.0 \mathrm{ml}$ $0.8 \%(\mathrm{w} / \mathrm{v})$ casein was added. The mixture was incubated for another 20 minutes. To stop the reaction, $2.0 \mathrm{ml}$ of $70 \%(\mathrm{v} / \mathrm{v})$ of chloric acid was added. Then the turbid suspension was centrifuged. The optical density of supernatant at $280 \mathrm{~nm}$ was measured. The inhibition percentage was calculated by the above formula.

\subsubsection{Effect on Membrane Stabilization}

The analysis was performed according to the method described by Shilpa et al. [46]. Fresh rat blood was collected in centrifuge tubes containing $200 \mathrm{mM} 0.5 \mathrm{ml}$ EDTA. The tubes were centrifuged at $3000 \mathrm{rpm}$ for 15 minutes and washed three times with an equal volume of physiological solution. The volume of RBC was measured and reduced as a $10 \%$ suspension with a physiological solution.

The reaction mixture $(4.5 \mathrm{ml})$ included $2.0 \mathrm{ml}$ of hypotonic physiological solution $(0.25 \% \mathrm{NaCl}), 1$ $\mathrm{ml}$ of $0.15 \mathrm{M}$ phosphate buffer $(\mathrm{pH} 7.4)$ and $1 \mathrm{ml}$ of CETH $(3.75,7.5,15.0 \mathrm{mg} / \mathrm{ml})$ in physiological solution. A similar volume of isotonic physiological solution was controlled. $0.5 \mathrm{ml}$ of $10 \%$ rat RBC was added to the physiological solution. The mixtures were incubated at $56^{\circ} \mathrm{C}$ for 30 minutes. Tubes were cooled under running tap water for 20 minutes. Mixtures were centrifuged at $3000 \mathrm{rpm}$ for 10 minutes. The optical density of supernatants was measured at $560 \mathrm{~nm}$. The percentage of stabilizing activity of the membrane was calculated by the formula:

$$
\% \text { Membrane stabilization }=\frac{\text { Abs control }- \text { Abs sample }}{\text { Abs control }} \times 100
$$

All studies of antiartrine activity of CETH in vitro were conducted in a three-fold repetition. Sodium diclofenac $(200 \mu \mathrm{g} / \mathrm{ml})$ was used as a comparison drug.

\subsection{Animals}

The experiment was conducted on male white rats of the Wistar line at the age of 10-12 weeks. The animals were kept in plastic cells in a laboratory vivarium under controlled environmental conditions (temperature $18-22^{\circ} \mathrm{C}$, relative humidity 50-65\%, 12 hours lighting cycle). Rats were kept on a standard food ration with free access to food and water. Before the experiment, the animals were acclimatized within two weeks.

All manipulations with animals were conducted in strict accordance with the Guide for the Care and Use of Laboratory Animals [8391]. The experiment was approved by the local bioethics committee of the Institute of Living Systems of North Caucasus Federal University (Study № 2020-003, Protocol № 4 of 22.09.2020). Every effort has been made to minimize animal suffering and reduce the number of rats used.

\subsection{Acute oral toxicity}

Toxicity assessment was performed on female white rats of Wistar line weighing 190-210 g according to OECD Test 425 recommendations [92]. The test for limit values was carried out by successive use of five animals with an interval of 48 hours. CETH was administered to the animals after night fasting and weighing in a dose of $2000 \mathrm{mg} / \mathrm{kg}$ through a stomach tube. After CETH administration, the animals were monitored for any clinical manifestations of toxicity every hour during the first four hours and then every day for the next two weeks. Weight, feed, and water 
consumption were recorded daily. On the 15th day after euthanasia of animals, pathomorphological assessment of vital organs for any pathological changes was made.

\subsection{Experimental protocol}

After acclimatization within 14 days, the animals were randomly divided into five groups of six rats in each as follows:

Group I: Healthy control.

Group II: Adjuvant arthritis control.

Group III: Adjuvant arthritis rats with $5 \mathrm{mg} / \mathrm{kg}$ Diclofenac sodium treatment.

Group IV: Adjuvant arthritis rats with $60 \mathrm{mg} / \mathrm{kg}$ CETH treatment.

Group V: Adjuvant arthritis rats with $120 \mathrm{mg} / \mathrm{kg}$ CETH treatment.

Arthritis was simulated by a single intradermal injection of $0.1 \mathrm{ml}$ of full adjuvant Freund in the pillow of the right hind leg of the rat. Animals were anesthetized by short-term inhalation of ether during the injection because the viscous nature of the adjuvant makes it difficult to administer and painful [93].

Manipulation was carried out in sterile conditions in the treatment room for animals far from the places where they were kept.

Animals of groups III, IV, and V received drug treatment for 14 consecutive days from 15 to 28 days after the adjuvant administration. CETH and Diclofenac sodium was administered orally in the volume of $10 \mathrm{ml} / \mathrm{kg}$ of body weight once a day. The rats of groups I and II were given a carrier (water) in the same amount for 14 days. CETH anti-arthritic activity was evaluated on injected animal paws.

\subsection{Micro-CT analysis}

Microtomography of animal paws was performed ex vivo using a micro-CT system (SkyScan 1176; Bruker micro-CT, Kontich, Belgium). For this purpose, the right hind legs were selected by cutting soft tissues and bone above the ankle joint during the autopsy.

Scanning protocol in Skyscan 1176 (10.0.0.0, Bruker-microCT, Kontich, Belgium) for rat hind legs: $65 \mathrm{kV}$ X-ray source voltage acceleration, $380 \mu \mathrm{A}$ X-ray source current, $\mathrm{Al} 1 \mathrm{~mm}$ filter, $17.74 \mu \mathrm{m}$ pixel size, $360^{\circ}$ tomographic rotation, $0.3^{\circ}$ shooting pitch, 4 frames averaging.

Microtomographic images of bones and joints were reconstructed using Nrecon software (version 1.7.1.0, Bruker, Kontich, Belgium). Uniform positioning and selection of a certain area of the reconstructed object was performed in DataViewer (version: 1.5.6.2, Bruker, Kontich, Belgium).

The analysis of microtomographic bone data was carried out by means of CTAn software (version: 1.18.4.0, Bruker, Kontich, Belgium), visualization was carried out in CTvox software (3.3.0r1403, Bruker-microCT, Belgium) [94,95]. The following parameters were evaluated: trabecular mineral density (trabecular BMD, mg/cm3); BV/TV - Percent bone volume; Tb.Pf - Trabecular pattern factor; Tb.Th - Trabecular thickness; Tb.Sp - Trabecular separation; BS/BV - Bone surface/bone volume; Tb.N - Trabecular number; SMI - Structure model index.

Swelling volumes of feet and osteophytes were calculated using CTAn software (version: 1.18.4.0, Bruker, Kontich, Belgium), visualization was performed in CTvox (3.3.0r1403, Bruker-microCT, Belgium) and CTvol (2.3.2.0, Bruker-microCT, Belgium). The results were documented with micro-CT images in 2- and 3D-images format.

The percentage of paw edema suppression was calculated from the average difference in paw volume in the experimental group treated and in the control group using the following formula [96]:

$$
\% \text { inhibition }=\frac{\text { increase in paw edema }(\text { control })-\text { increase in paw edema (test) }}{\text { increase in paw edema }(\text { control })} \times 100
$$


After micro-CT scanning, the animal paws were fixed in $10 \%$ buffered formalin solution for 72 hours. They were decalcified in a decalcifying solution of SoftiDec (Biovitrum, St. Petersburg, Russia) for 30 days. After that, they were dehydrated in isopropyl alcohol with subsequent soaking and entering into medical paraffin Histomix (Biovitrum, St. Petersburg, Russia). Histological slices with a thickness of 5-6 microns were made on sledge microtome MS-2 (ATM-practica, St. Petersburg, Russia). The ready slices were stained with hematoxylin and eosin, followed by histopathological analysis.

Evaluation of histological micropreparation was performed using laboratory microscope of research class Axio Imager 2 (A2) (Carl Zeiss Microscopy, Oberkochen, Germany) at $\times 50$ magnification with image fixation with the help of specialized AxioCam MRc5 camera (Carl Zeiss Microscopy, Oberkochen, Germany) and Zen 2 software (Carl Zeiss Microscopy, Oberkochen, Germany).

The histopathological analysis included assessing changes in bone tissue (osteolysis), joint inflammation, and cartilage degeneration. The degree of severity of the pathological changes was classified by semi-quantitative assessment of histological changes according to a modified scale by Bendele et al. [97] and Mankin et al. [98].

The changes in bone tissue were classified into five categories (0-5): 0 - normal; 1 - minimal (small resorption areas in the distal part of the tibia or cortical bone, not very visible at slight magnification, rare osteoclasts); 2 - soft (more numerous resorption areas in the distal part of the tibia or cortical bone, not very visible at slight magnification, osteoclasts more numerous); 3 moderate (obvious resorption of medullary trabecular and cortical bone without complete cortical defects, loss of some medullary trabeculars, the lesion is visible at low magnification, osteoclasts are more numerous); 4 - noted (full thickness defects in the cortical bone, often with a distortion of the profile of the remaining cortical surface, a pronounced loss of brain matter of the distal tibia, numerous osteoclasts, without resorption in the smaller legs of the bone); 5 - Heavy (full thickness defects in the cortical bone, often with a distortion of the profile of the remaining cortical surface, a marked loss of medullary bone of the distal tibia, numerous osteoclasts, resorption is also present in the smaller foreplate bone).

Expression of joint inflammation was classified into five categories (0-5): 0 - normal; 1 - minimal infiltration of inflammatory cells in the periarticular tissue; 2 - mild infiltration; 3 - moderate infiltration with moderate swelling; 4 - severe infiltration with severe swelling; 5 - severe infiltration with severe swelling.

The degree of cartilage degeneration was classified according to the ball system (0-9): surface structure (1 point - bumps, erosion; 2 points - cracks; 3 points - delamination); cell composition (1 point - a slight decrease in the number of chondrocytes; 2 points - a significant decrease in the number of chondrocytes; 3 points - no cells); cell proliferation (1 point - isogenic groups of chondrocytes by 2 cells in the group; 2 points - isogenic groups of chondrocytes by 2 and 3 cells in the group; 3 points - proliferation centers of more than 3 cells in the group).

\subsection{Immunohistochemistry analysis of caspase-3 expression levels}

The immunohistochemical study of caspase- 3 was conducted following the method described by Shafiey et al. [57] in some modification. Briefly, dewaxing and rehydration of ankle slices were performed, followed by buffer washing and heating in a water bath at $95^{\circ} \mathrm{C}$ for one hour. Further, to reduce the effect of endogenous peroxidase, the slices were placed in $0.3 \% \mathrm{H}_{2} \mathrm{O}_{2}$ solution for 10 minutes. Then the slices were incubated during the night at $4^{\circ} \mathrm{C}$ with the primary antibody against caspase-3 (Thermo Fisher Scientific, Fremont, USA). The cuts were washed with a buffer and incubated with the HRP secondary antibody Quanto polymer (Thermo Fisher Scientific, Fremont, USA) for 10 minutes at $27^{\circ} \mathrm{C}$. After washing with distilled imaging water, a DAB solution was applied to the cuts (1 drop of DAB Quanto chromogen $+1.0 \mathrm{ml}$ of DAB Quanto substrate). After washing, the slices were dyed with hematoxylin, dehydrated in xylene, placed under cover glass, and studied with the Axio Imager 2 (A2) microscope (Carl Zeiss Microscopy, Oberkochen, Germany). 
The caspase-3 expression level was quantitatively determined by densitometric analysis of digital images using Image J software (Bethesda, USA).

\subsection{Statistical analysis}

The results were expressed as mean \pm SEM (standard error mean). Statistical analyses were conducted with GraphPad Prism for Windows, Version 6.01 (GraphPad Software, San Diego, CA, USA). The statistical analysis was performed by one-way variance analysis (ANOVA). A p-value < 0.05 was considered statistically significant.

\section{Conclusions}

The results obtained at the morphological level confirm the hypothesis that hydrolysate tissue of the chicken embryo shows a pronounced dose-dependent anti-arthritic effect in adjuvant-induced joint damage in rats, which is the closest model to rheumatoid arthritis in humans.

This study has a potential theoretical strategy for the safe correction of this pathological process and, for the first time, shows that hydrolyzate of chicken embryo tissue may be a powerful nutraceutical agent or component of a functional food product in the treatment of rheumatoid arthritis.

The therapeutic efficacy of CETH may be due to antioxidant activity, anti-inflammatory, osteoanabolic activity, and possible immunotropic action. However, more in-depth and long-term studies are needed to finally examine this effect and determine the detailed mechanisms of CETH action at the molecular level.

Author Contributions: Conceptualization, I.R., L.T., and W.-D.G.; methodology, I.R., S.P., S.A., and A.D.; software, I.R., and S.P.; validation, I.R., W.-D.G., and L.T.; formal analysis, S.P., S.A., and M.S.; investigation, I.R.; L.T., S.P.; resources, I.R., A.D., and S.K.; data curation, I.R., L.T.; writing-original draft preparation, I.R., K.D., S.P., and W.-D.G.; writing - review and editing, M.B., N.E., I.R.; L.T., T.F., M.V., W.-D.G., and S.P.; visualization, S.P., and M.S.; supervision, I.R., W.-D.G., and L.T.; project administration, I.R.; funding acquisition, I.R., W.-D.G., S.K., and A.D. All authors have read and agreed to the published version of the manuscript.

Conflicts of Interest: The authors declare no conflict of interest.

\section{Abbreviations}

$\begin{array}{ll}\text { CETH } & \text { Chicken embryo tissue hydrolyzate } \\ \text { Micro-CT } & \text { Computer microtomography } \\ \text { NSAID } & \text { Non-steroidal anti-inflammatory drugs } \\ \text { DMARD } & \text { Disease-modifying anti rheumatoid drugs } \\ \text { BMD } & \text { Bone mineral density } \\ \text { BV/TV } & \text { Percent bone volume } \\ \text { Tb.Pf } & \text { Trabecular pattern factor } \\ \text { Tb.Th } & \text { Trabecular thickness } \\ \text { Tb.Sp } & \text { Trabecular separation } \\ \text { BS/BV } & \text { Bone surface/bone volume } \\ \text { Tb.N } & \text { Trabecular number }\end{array}$

\section{References}

1. Firestein, G.S.; McInnes, I.B. Immunopathogenesis of Rheumatoid Arthritis. Immunity 2017, 46, $183-196$. doi:10.1016/j.immuni.2017.02.006

2. Schett, G.; Gravallese, E. Bone erosion in rheumatoid arthritis: mechanisms, diagnosis and treatment. Nat. Rev. Rheumatol. 2012, 8, 656-664.

3. Kumar, L.D.; Karthik, R.; Gayathri, N.; Sivasudha, T. Advancement in contemporary diagnostic and therapeutic approaches for rheumatoid arthritis. Biomed Pharmacother 2016, 79, 52-61. doi:10.1016/j.biopha.2016.02.001 
4. Balsa, A.; Lojo-Oliveira, L.; Alperi-López, M.; García-Manrique, M.; Ordóñez-Cañizares, C.; Pérez, L.; ... Martín-Mola; E. Prevalence of Comorbidities in Rheumatoid Arthritis and Evaluation of Their Monitoring in Clinical Practice: The Spanish Cohort of the COMORA Study. Reumatol Clin (English Edition) 2019, 15, 102-108. doi:10.1016/j.reumae.2017.06.003

5. Myasoedova, E.; Davis, J.M.; Achenbach, S.J.; Matteson, E.L.; Crowson, C.S. Trends in Prevalence of Functional Disability in Rheumatoid Arthritis Compared With the General Population. Mayo Clin. Proc. 2019, 94, 1035-1039. doi:10.1016/j.mayocp.2019.01.002

6. Mateen, S.; Zafar, A.; Moin, S.; Khan, A.Q.; Zubair, S. Understanding the role of cytokines in the pathogenesis of rheumatoid arthritis. Clin. Chim. Acta 2016, 455, 161-171. doi:10.1016/j.cca.2016.02.010

7. Scherer, H. U., Häupl, T., Burmester, G. R. The etiology of rheumatoid arthritis. Journal of Autoimmunity 2020, 102400. doi:10.1016/j.jaut.2019.102400

8. Van Vollenhoven, R.F. General treatment aspects, Biol. Treat. Rheum. Arthritis, Springer International Publishing, Cham, 2016; pp. 9-27, doi: 10.1007/978-3-319-13108-5_2.

9. Law, S.T.; Taylor, P.C. Role of Biological Agents in Treatment of Rheumatoid Arthritis. Pharmacol. Res. 2019, 104497. doi:10.1016/j.phrs.2019.104497

10. Grimm, W.-D.; Giesenhagen, B.; Hakki, S.; Schau, I.; Sirak, S.; Sletov, A.; Varga, G.; Vukovic M.A.; Widera, D. Translational Research and Therapeutic Applications of Neural Crest-Derived Stem Cells in Regenerative Periodontology. Curr. Oral Health Rep. 2015, 2, 266-274. doi:10.1007/s40496-015-0067-6

11. Zeuner, M.-T.; Didenko, N.N.; Humphries, D.; Stergiadis, S.; Morash, T.M.; Patel, K.; Grimm, W.-D.; Widera, D. Isolation and Characterization of Neural Crest-Derived Stem Cells From Adult Ovine Palatal Tissue. Front. Cell Dev. Biol. 2018, 6. doi:10.3389/fcell.2018.00039

12. Kochkina, E.N.; Kotova, P.D.; Enukashvily, N.I.; Kolesnikov, S.S. cGMP-Dependent Protein Kinase Modulates the Sensitivity of Mesenchymal Stromal Cells to Purinergic Agonists. Biochemistry (Moscow), Supplement Series A: Membr. Cell Biol. 2019, 13, 283-287. doi:10.1134/s1990747819030152

13. Oray, M.; Abu Samra, K.; Ebrahimiadib, N.; Meese, H.;Foster, C.S. Long-term side effects of glucocorticoids. Expert Opin. Drug Saf. 2016, 15, 457-465. doi:10.1517/14740338.2016.1140743

14. Dyadyk, A.I.; Kugler, T.E. Side effects of non-steroidal anti-inflammatory drugs. Consilium Medi cum. 2017, 19, 94-99. doi: 10.26442/2075-1753_19.12.94-99

15. Lekander, I.; Borgström, F.; Lysholm, J.; van Vollenhoven, R.F.; Lindblad, S.; Geborek, P.; Kobelt, G. The cost-effectiveness of TNF-inhibitors for the treatment of rheumatoid arthritis in Swedish clinical practice. Eur. J. Health Econ. 2012, 14, 863-873.

16. Skurikhin, E.G.; Pershina, O.V.; Pakhomova, A.V.; Pan, E.S.; Krupin, V.A.; Ermakova, N.N.; Grimm, W.-D.; Dygai, A.M. Endothelial progenitor cells as pathogenetic and diagnostic factors, and potential targets for GLP-1 in combination with metabolic syndrome and chronic obstructive pulmonary disease. Int. J. Mol. Sci. 2019, 20. doi:10.3390/ijms20051105

17. Wang, Y.; Yu, D.; Liu, Z.; Zhou, F.; Dai, J.; Wu, B.; Liu, H. Exosomes from embryonic mesenchymal stem cells alleviate osteoarthritis through balancing synthesis and degradation of cartilage extracellular matrix. Stem Cell Research and Therapy 2017, 8. doi:10.1186/s13287-017-0632-0

18. Haque, N.; Widera, D.; Abu Kasim, N.H. Stem Cells from Human Extracted Deciduous Teeth Expanded in Foetal Bovine and Human Sera Express Different Paracrine Factors After Exposure to Freshly Prepared Human Serum. Adv. Exp. Med. Biol. 2019, 1084, 175-186. doi:10.1007/5584_2018_299

19. Grimm, W.-D.; Widera, D. Secretome of Stem Cells as an Alternative to Stem Cell Transplantation. Genes and Cells 2019, 14, 12.

20. Zeuner, M.T.; Patel, K.; Denecke, B.; Giebel, B.; Widera, D. Paracrine effects of TLR4-polarised mesenchymal stromal cells are mediated by extracellular vesicles. J. Transl. Med. 2016, 14. doi: 10.1186/s12967-016-0794-Z

21. Mellows, B.; Mitchell, R.; Antonioli, M.; Kretz, O.; Chambers, D.; Zeuner, M.T.; ... Patel, K. Protein and Molecular Characterization of a Clinically Compliant Amniotic Fluid Stem Cell-Derived Extracellular Vesicle Fraction Capable of Accelerating Muscle Regeneration Through Enhancement of Angiogenesis. Stem Cells Dev, 2017, 26, 1316-1333. doi:10.1089/scd.2017.0089

22. Jacob, J.; Amalraj, A.; Raj, K.K.J.; Divya, C.; Kunnumakkara, A.B.; Gopi, S. A novel bioavailable hydrogenated curcuminoids formulation (CuroWhite ${ }^{\mathrm{TM}}$ ) improves symptoms and diagnostic indicators in rheumatoid arthritis patients - A randomized, double blind and placebo controlled study. Journal of Traditional and Complementary Medicine 2018, 9, 346-352. doi: 10.1016/j.jtcme.2018.06.001 
23. Dudics, S.; Langan, D.; Meka, R.; Venkatesha, S.; Berman, B.; Che, C.-T.; Moudgil, K. Natural Products for the Treatment of Autoimmune Arthritis: Their Mechanisms of Action, Targeted Delivery, and Interplay with the Host Microbiome. Int. J. Mol. Sci., 2018, 19, 2508. doi:10.3390/ijms19092508

24. Nasuti, C.; Fedeli, D.; Bordoni, L.; Piangerelli, M.; Servili, M.; Selvaggini, R.; Gabbianelli, R. Anti-Inflammatory, Anti-Arthritic and Anti-Nociceptive Activities of Nigella sativa Oil in a Rat Model of Arthritis. Antioxidants 2019, 8, 342. doi:10.3390/antiox8090342

25. Wang, X.; Fang, G.; Yang, Y.; Pang, Y. The newly discovered natural compounds against rheumatoid arthritis-an overview. Phytochem.y Lett. 2019, 34, 50-58. doi:10.1016/j.phytol.2019.09.011

26. Jeong Dong Park, M.D.; Sang-Il Lee, M.D.; A Ram Kim, M.D.; Jong Moon Park, M.D.; Sang-Yeop Shin, M.D.; Jun Hwa Shin, M.D.; Seung Won Moon, M.D.; Hyun Park, M.D.; Min-Kyun Oh, M.D.; Hee Suk Shin, M.D. The Effect of Human Placental Extract on Rheumatoid Arthritis in an Animal Model. Ann. Rehabilit. Med. 2012, 36, 197-206. doi: 10.5535/arm.2012.36.2.197

27. Raines, A.L.; Shih, M.-S.; Chua, L.; Su, C.-W.; Tseng, S.C.G.; O'Connell, J. Efficacy of Particulate Amniotic Membrane and Umbilical Cord Tissues in Attenuating Cartilage Destruction in an Osteoarthritis Model. Tissue Engineering Part A 2017, 23, 12-19. doi:10.1089/ten.tea.2016.0088

28. Lutsenko, E.D.; Ostankov, M.V.; Bondarovich, N.A.; Goltsev, A.N. Influence of Application of Cryopreserved Placental Cell Suspension on Indices of Peripheral Blood and Bone Marrow of Animals with Adjuvant Arthritis. Probl. Cryobiol. Cryomed. 2019, 29, 028-043. doi:10.15407/cryo29.01.028

29. Wang, L.; Song, X.; Cui, H.; Man, S.; Li, W.; Muluye, R.A.; ... Cai, Y. Antifatigue effects of peptide isolated from sheep placenta. Chinese Herbal Medicines 2018. doi:10.1016/j.chmed.2018.06.005

30. Heo, J.H.; Heo, Y.; Lee, H.J.; Kim, M.; Shin, H.Y. Topical anti-inflammatory and anti-oxidative effects of porcine placenta extracts on 2,4-dinitrochlorobenzene-induced contact dermatitis. BMC Complementary and Alternative Medicine 2018, 18, 331. doi: 10.1186/s12906-018-2396-1

31. Kim, T.H.; Choi, J.-Y.; Kim, K.H.; (...), Kim, J.-I.; Joo, M. Hominis placenta Suppresses Acute Lung Inflammation by Activating Nrf2. Am. J. Chin. Med. 2018, 46, 801-817. doi: 10.1142/S0192415X18500428

32. Bak, D.; Na, J.; Choi, M.; Lee, B.; Oh, C.; Kim, J.; ... Kim, B. Anti-apoptotic effects of human placental hydrolysate against hepatocyte toxicity in vivo and in vitro. Int. J. Mol. Med. 2018, 42, 2569-2583.

33. Han, N.-R., Park, C.-L., Kim, N.-R., (...), Jeong, H.-J., Kim, H.-M. Protective effect of porcine placenta in a menopausal ovariectomized mouse. Reproduction 2015, 150, 173-181. doi: 10.1530/REP-15-0157

34. Pogozhykh, O.; Prokopyuk, V.; Figueiredo, C.; Pogozhykh, D. Placenta and Placental Derivatives in Regenerative Therapies: Experimental Studies, History, and Prospects. Stem Cells International 2018, 1-14. doi: $10.1155 / 2018 / 4837930$

35. Liu, J.J. Nutritional compositions of chicken embryo from different species and incubation time. Food and Nutr. in China 2007, 5, 14-16.

36. Li, Xi.; Su, Y.; Sun, J.; Yang, Y. Chicken embryo extracts enhance spleen lymphocyte and peritoneal macrophages function. Journal of Ethnopharmacol. 2012, 144, 255-260.

37. Kim, S.; Kim, Y.; Baek, I.K.; Auh, J. Carnosine and anserine in chicken: distribution, age-dependency and their anti-glycation activity. Korean Journal of Food Sci. Ani. Resour. 2012, 32, 45-48.

38. Rzhepakovsky, I.V.; Timchenko, L.D.; Areshidze, D.A.; Avanesyan, S.S.; Budkevich, E.V.; Piskov, S.I.; Mannino, S.; Lodygin, A.D.; Kovalev, D.A.; Kochergin, S.G. Antioxidant activity of chicken embryo tissues powder obtained by different methods of hydrolysis. J. Hyg. Eng. Des. 2019, 27, 127-133.

39. Meram, C.; $W u, J$. Anti-inflammatory effects of egg yolk livetins ( $\alpha, \beta$, and $\gamma$-livetin) fraction and its enzymatic hydrolysates in lipopolysaccharide-induced RAW 264.7 macrophages. Food Res. Int. 2017, 100, 449-459. doi:10.1016/j.foodres.2017.07.032

40. Sun, H.; Ye, T.; Wang, Y.; Wang, L.; Chen, Y.; Li, B. Antioxidant activities of chick embryo egg hydrolysates. Food Science \& Nutrition 2013, 2, 58-64. doi:10.1002/fsn3.77

41. Duan, X.; Ocen, D.; Wu, F.; Li, M.; Yang, N.; Xu, J.; ... Xu, X. Purification and characterization of a natural antioxidant peptide from fertilized eggs. Food Res. Int. 2014, 56, 18-24. doi:10.1016/j.foodres.2013.12.016

42. Li, X.; Su, Y.; Sun, J.; Yang, Y. Chicken embryo extracts enhance spleen lymphocyte and peritoneal macrophages function. J. Ethnopharmacol. 2012, 144, 255-260. doi:10.1016/j.jep.2012.09.001

43. Areshidze, D.; Timchenko, L.; Rzhepakovsky, I.; Kozlova, M.; Syomin, I. Anti-inflammatory effect of NICA-EM in rodent models of acute inflammation. Pharmacologyonline 2015, 3, 76-83. 
44. Areshidze, D.A.; Kozlova, M.A.; Kusnetsova, I.A.; Makartseva, L.A.; Timchenko L.D.; Rzhepakovsky I V. Anti-inflammatory effect of Nicavet-2500 in rodent models of acute inflammation. Journal of Pharmacy and Nutrition Sciences 2018, 835-41.

45. Oikonomopoulou, K.; Diamandis, E.; Hollenberg, M.; Chandran, V.. Proteinases and their receptors in inflammatory arthritis: an overview. Na.t Rev. Rheumatol 2018, 14, 170-180. doi:10.1038/nrrheum.2018.17

46. Shilpa K.; Chacko N.; Shetty P. Investigation of anti-arthritic activity (in-vitro models) of Hibiscus hispidissimus Griffith. The Journal of Phytopharmacology 2018; 7, 60-65.

47. Almarestani, L.; Fitzcharles, M.-A.; Bennett, G.J.; Ribeiro-da-Silva, A. Imaging studies in Freund's complete adjuvant model of regional polyarthritis, a model suitable for the study of pain mechanisms, in the rat. Arthritis Rheum. 2011, 63, 1573-1581. doi:10.1002/art.30303

48. Sevilla, R.S.; Cruz, F.; Chiu, C.-S.; Xue, D.; Bettano, K.A.; Zhu, J.; ... Zhang, W. Development and optimization of a high-throughput micro-computed tomography imaging method incorporating a novel analysis technique to evaluate bone mineral density of arthritic joints in a rodent model of collagen induced arthritis. Bone 2015, 73, 32-41. doi:10.1016/j.bone.2014.11.014

49. Buckland-Wright, J.C.; Macfarlane, D.G.; Lynch, J.A.; Jasani, M.K.; Bradshaw, C.R. Joint space width measures cartilage thickness in osteoarthritis of the knee: high resolution plain film and double contrast macroradiographic investigation. Ann Rheum Dis 1995; 54, 263-268.

50. Pfeil, A.; Renz, D.M.; Hansch, A.; Kainberger, F.; Lehmann, G.; Malich, A.; ... Böttcher, J. The usefulness of computer-aided joint space analysis in the assessment of rheumatoid arthritis. Joint Bone Spine 2013, 80, 380385. doi:10.1016/j.jbspin.2012.10.022

51. Noguchi, M.; Kimoto, A.; Sasamata, M.; Miyata, K. Micro-CT imaging analysis for the effect of celecoxib, a cyclooxygenase-2 inhibitor, on inflammatory bone destruction in adjuvant arthritis rats. J. Bone Miner. Metab. 2008, 26, 461-468. doi:10.1007/s00774-008-0855-3

52. Kotova, P.D.; Kochkina, E.N.; Lyamin, O.O.; Rogachevskaja, O.A.; Korolenko, N.P.; Ivashin, D.S.; Bystrova, M.F.; Enukashvily, N.I.; Kolesnikov, S.S. Calcium signaling mediated by aminergic GPCRs is impaired by the PI3K inhibitor LY294002 and its analog LY303511 in a PI3K-independent manner [published online ahead of print, 2020 May 13]. Eur. J. Pharmacol. 2020, 173182. doi: 10.1016/j.ejphar.2020.173182

53. Ito, M. (n.d.). CT-Based Microstructure Analysis for Assessment of Bone Fragility. Advanced Bioimaging Technologies in Assessment of the Quality of Bone and Scaffold Materials, 2007, 417-429. doi:10.1007/978-3-540-45456-4_25

54. Kim, Y.H.; Kang, J.S. Micro-computed tomography evaluation and pathological analyses of female rats with collagen-induced arthritis. J. Vet.Sci. 2015, 16, 165. doi:10.4142/jvs.2015.16.2.165

55. Hayatullina, Z.; Muhammad, N.; Mohamed, N.; Soelaiman I.-N. Virgin Coconut Oil Supplementation Prevents Bone Loss in Osteoporosis Rat Model. Evid Based Complement Alternat Med. 2012, 12, 1-8. doi:10.1155/2012/237236

56. Wu, Z.; Nagata, K.; Iijima, T. Involvement of sensory nerves and immune cells in osteophyte formation in the ankle joint of adjuvant arthritic rats. Histochem. Cell Biol. 2002, 118, 213-220. doi:10.1007/s00418-002-0443-x

57. Shafiey, S.I.; Mohamed, W.R.; Abo-Saif, A.A. Paroxetine and rivastigmine mitigates adjuvant-induced rheumatoid arthritis in rats: Impact on oxidative stress, apoptosis and RANKL/OPG signals. Lfs.2018. doi:10.1016/j.lfs.2018.09.046

58. Abdel-Maged, A.E.; Gad, A.M.; Wahdan, S.A.; Azab, S.S. Efficacy and safety of Ramucirumab and methotrexate co-therapy in rheumatoid arthritis experimental model: Involvement of angiogenic and immunomodulatory signaling. Toxicol. Appl. Pharmacol. 2019, 114702.

59. Mobasheri, A. Future Cell and Gene Therapy for Osteoarthritis (OA): Potential for Using Mammalian Protein Production Platforms, Irradiated and Transfected Protein Packaging Cell Lines for Over-Production of Therapeutic Proteins and Growth Factors. doi:10.1007/5584_2019_457

60. Benlidayi, M.E.; Tatli, U.; Salimov, F.; Tukel, H.C.; Yuksel, O. Comparison of autogenous and allograft bone rings in surgically created vertical bone defects around implants in a sheep model. Clin. Oral Impl. Res. 2018, 29, 1155-1162.

61. Pundarikakshudu, K. Antiinflammatory and Antiarthritic Activities of Some Foods and Spices. Bioactive Food as Dietary Interventions for Arthritis and Related Inflammatory Diseases 2019, 51-68. doi:10.1016/b978-0-12-813820-5.00004-0 
62. Bustamante, M.F.; Agustí-Perez, M.; Cedola, F.; Coras, R.; Narasimhan, R.; Golshan, S.; Guma, M. Design of an anti-inflammatory diet (ITIS diet) for patients with Rheumatoid arthritis. Contemporary Clinical Trials Communications 2020, 17, 100524. doi: 10.1016/j.conctc.2020.100524

63. Vadell, A.K.E.; Bärebring, L.; Hulander, E.; Gjertsson, I.; Lindqvist, H.M.; Winkvist, A. Anti-inflammatory Diet In Rheumatoid Arthritis (ADIRA) - a randomized, controlled crossover trial indicating effects on disease activity. Am. J. Clin. Nutr. 2020, 00, 1-11. doi:10.1093/ajcn/nqaa019

64. Chakrabarti, S.; Jahandideh, F.; Wu, J. Food-Derived Bioactive Peptides on Inflammation and Oxidative Stress. BioMed Research International 2014, 1-11.

65. Chalamaiah, M.; Yu, W.; Wu, J. Immunomodulatory and anticancer protein hydrolysates (peptides) from food proteins: A review. Food Chemistry 2018, 245, 205-222.

66. Hatori, M., Ohki, K., Hirano, S., Yang, X.-P., Kuboki, H., Abe, C. Effects of a Casein Hydrolysate Prepared from Aspergillus oryzae Protease on Adjuvant Arthritis in Rats. Biosci. Biotechnol. Biochem. 2008, 72, 19831991.

67. Chandra, K.; Salman, A.S.; Mohd, A.; Sweety, R.; Ali, K.N. Protection against FCA induced oxidative stress induced DNA damage as a model of arthritis and In vitro anti-arthritic potential of Costus speciosus Rhizome extract. International Journal of Pharmacognosy and Phytochemical Research 2015. 7, 383-389.

68. Bihani, G.V.; Rojatkar, S.R., Bodhankar, S. L. Anti-arthritic activity of methanol extract of Cyathocline purpurea (whole plant) in Freund's complete adjuvant-induced arthritis in rats. Biomedicine $\mathcal{E}$ Aging Pathology 2014, 4, 197-206. doi:10.1016/j.biomag.2014.04.007

69. Jaswal, S.; Mehta, H.C.; Sood, A.K.; Kaur, J. Antioxidant status in rheumatoid arthritis and role of antioxidant therapy. Clin. Chim. Acta 2018, 338, 123-129. doi:10.1016/j.cccn.2003.08.011

70. Verma, I.; Syngle, A.; Krishan, P. Therapeutic effects of spironolactone on a collagen-induced arthritis model of rheumatoid arthritis. The Egyptian Rheumatologist 2017, 39, 57-63. doi:10.1016/j.ejr.2016.06.002

71. Bhowmick, K.; Chakraborti, G.; Gudi, N.; Moideen, A.K.; Shetty, H. Free radical and antioxidant status in rheumatoid arthritis. Indian J. Rheumatol. 2008, 3, 8-12. doi:10.1016/s0973-3698(10)60073-8

72. Vasanthi, P.; Nalini, G.; Rajasekhar, G. Status of oxidative stress in rheumatoid arthritis. Int.J. Rheum.Dis. 2009, 12, 29-33. doi:10.1111/j.1756-185x.2009.01375.x

73. Tak, P.P.; Klapwijk, M.S.; Broersen, S.F.; van de Geest, D.A.; Overbeek, M.; Firestein, G.S. Arthritis Research 2000, 2, 229. doi:10.1186/ar92

74. Lee, H.; Park, Y.; Ahn, C.W.; Park, S.H.; Jung, E.Y.; Suh, H.J. Deer Bone Extract Suppresses Articular Cartilage Damage Induced by Monosodium Iodoacetate in Osteoarthritic Rats: An In Vivo MicroComputed Tomography Study. J. Med. Food 2014, 17, 701-706. doi:10.1089/jmf.2013.2959

75. Drafi, F.; Bauerova, K.; Valachova, K.; Ponist, S.; Mihalova, D.; Juranek, I.; Boldyrev, A.; Hrabarova, E.; Soltes, L. Carnosine inhibits degradation of hyaluronan induced by free radical processes in vitro and improves the redox imbalance in adjuvant arthritis in vivo. Neuro Endocrinol. Lett. 2010, 31, 96-100.

76. Ponist, S.; Drafi, F.; Kuncirova, V.; Mihalova, D.; Rackova, L.; Danisovic, L.; ... Bauerova, K. Effect of Carnosine in Experimental Arthritis and on Primary Culture Chondrocytes. Oxidative Medicine and Cellular Longevity 2016, 2016, 1-11. doi:10.1155/2016/8470589

77. Zhao, J.M.; Chen, X.; Cheng, K.; Shi, Q.; Peng, K. Anserine and glucosamine supplementation attenuates the levels of inflammatory markers in rats with rheumatoid arthritis. AMB Expr. 2020, 10. doi:10.1186/s13568-020-00987-8

78. Cui, X.; Li, Y.; Yang, L.; You, L.; Wang, X.; Shi, C.; ... Guo, X. Peptidome analysis of human milk from women delivering macrosomic fetuses reveals multiple means of protection for infants. Oncotarget 2016, 7. doi:10.18632/oncotarget.11532

79. Cai, J.; Li, X.; Du, H.; Jiang, C.; Xu, S.; Cao, Y. Immunomodulatory significance of natural peptides in mammalians: promising agents for medical application. Immunobiology 2020, 151936. doi:10.1016/j.imbio.2020.151936

80. Tanaka, S.; Murakami, T.; Horikawa, H.; Sugiura, M.; Kawashima, K.; Sugita, T. Suppression of arthritis by the inhibitors of dipeptidyl peptidase IV. Int. J. Immunopharmac. 1997, 19, 15-24. doi:10.1016/s0192-0561(97)00004-0

81. Tanaka, S.; Murakami, T.; Nonaka, N.; Ohnuki, T.; Yamada, M.; Sugita, T. Anti-arthritic effects of the novel dipeptidyl peptidase IV inhibitors TMC-2A and TSL-225. Immunopharmacology 1998, 40, 2126. doi:10.1016/s0162-3109(98)00014-9 
82. Williams, Y.N.; Baba, H.; Hayashi, S.; Ikai, H.; Sugita, T.; Tanaka, S.; .. Kubota, T. Dipeptidyl peptidase IV on activated $\mathrm{T}$ cells as a target molecule for therapy of rheumatoid arthritis. Clin.Exp. Immunol. 2003, 131, 68-74. doi:10.1046/j.1365-2249.2003.02020.x

83. Huang, S.-L.; Jao, C.-L.; Ho, K.-P.; Hsu, K.-C. Dipeptidyl-peptidase IV inhibitory activity of peptides derived from tuna cooking juice hydrolysates. Peptides 2012, 35, 114-121. doi:10.1016/j.peptides.2012.03.006

84. Amso, Z.; Cornish, J.; Brimble, M.A. Short Anabolic Peptides for Bone Growth. Medicinal Research Reviews, 2016, 36, 579-640. doi:10.1002/med.21388

85. Mada, S.B.; Reddi, S.; Kumar, N.; Vij, R.; Yadav, R.; Kapila, S.; Kapila, R. Casein-derived antioxidative peptide prevents oxidative stress-induced dysfunction in osteoblast cells. PharmaNutrition 2018, 6, 169-179. doi:10.1016/j.phanu.2018.07.001

86. Liu, H. The role of apoptosis in rheumatoid arthritis. Curr. Opin. Pharmacol. 2003, 3, $317-322$. doi:10.1016/s1471-4892(03)00037-7

87. Pandurangan, M.; Enkhtaivan, G.; Kim, D.H. Therapeutic efficacy of natural dipeptide carnosine against human cervical carcinoma cells. J. Mol. Recognit. 2016, 29, 426-435. doi:10.1002/jmr.2541

88. Pandurangan, M.; Mistry, B.; Enkhataivan, G.; Kim, D.H. Efficacy of carnosine on activation of caspase 3 and human renal carcinoma cell inhibition. Int. J. Biol. Macromol. 2016, 92, 377-382. doi:10.1016/j.ijbiomac.2016.07.044

89. Timchenko, L.D.; Rzhepakovsky, I.V.; Vakulin, V.N.; Blazhnova, G.N. Method of preparation of a low-molecular complex of activated embryonic (NIKA-EM). Patent 2015, № 2560845 of the RF.

90. Niazi, S.G.; Uttra, A.M.; Qaiser, M.N.; Ahsan, H. Appraisal of anti-arthritic and nephroprotective potential of Cuscuta reflexa. Pharm. Biol. 2017, 55, 792-798. doi:10.1080/13880209.2017.1280513

91. National Research Council. Guide for the Care and Use of Laboratory Animals: Eighth Edition. Washington, DC: The National Academies Press. 2011. doi:10.17226/12910

92. OECD, T. No. 425: Acute Oral Toxicity: Up-and-Down Procedure, OECD Guidelines for the Testing of Chemicals, vol. 4, OECD Publishing, Paris, France, 2008.

93. Bihani, G.V.; Rojatkar, S.R.; Bodhankar, S.L. Anti-arthritic activity of methanol extract of Cyathocline purpurea (whole plant) in Freund's complete adjuvant-induced arthritis in rats. Biomed. Aging Pathol. 2014, 4, 197-206. doi:10.1016/j.biomag.2014.04.007

94. Orhan, K. (Ed.). Micro-computed tomography (micro-CT) in medicine and engineering. Springer Nature Switzerland AG. 2020; 312. doi:10.1007/978-3-030-16641-0.

95. Sadyrin, E.; Swain, M.; Mitrin, B.; Rzhepakovsky, I.; Nikolaev, A.; Irkha, V.; Yogina, D.; Lyanguzov, N.; Maksyukov, S.; Aizikovich, S. Characterization of Enamel and Dentine about a White Spot Lesion: Mechanical Properties, Mineral Density, Microstructure and Molecular Composition. Nanomaterials 2020, 10, 1889. doi:10.3390/nano10091889

96. Shabbir, A.; Batool, S.A.; Basheer, M.I.; Shahzad, M.; Sultana, K.; Tareen, R.B.; ... Saeed-ul-Hassan. Ziziphora clinopodioides ameliorated rheumatoid arthritis and inflammatory paw edema in different models of acute and chronic inflammation. Biomed. Pharmacother. 2018, 97, 1710-1721. doi:10.1016/j.biopha.2017.11.118

97. Bendele, A., Mccomb, J.; Gould, T.; Mcabee, T.; Sennello, G.; Chlipala, E. Guy, M. Animal Models of Arthritis: Relevance to Human Disease. Toxicologic Pathology, 1999, 27, $134-142$. doi:10.1177/019262339902700125

98. Mankin, H.J.; Dorfman, H.; Lippiello, L.; Zarins, A. Biochemical and metabolic abnormalities in articular cartilage from osteo-arthritic human hips. II. Correlation of morphology with biochemical and metabolic data. J. Bone Joint Surg. Am. 1971, 53, 523-537. 